\title{
Quantification of Internalized Silica Nanoparticles via STED Microscopy
}

\author{
Henrike Peuschel, Thomas Ruckelshausen, Christian Cavelius, and Annette Kraegeloh
}

Leibniz-Institute for New Materials (INM), Campus D2 2, 66123 Saarbruecken, Germany

Correspondence should be addressed to Annette Kraegeloh; annette.kraegeloh@inm-gmbh.de

Received 1 October 2014; Accepted 24 February 2015

Academic Editor: Sehyun Shin

Copyright ( 2015 Henrike Peuschel et al. This is an open access article distributed under the Creative Commons Attribution License, which permits unrestricted use, distribution, and reproduction in any medium, provided the original work is properly cited.

The development of safe engineered nanoparticles (NPs) requires a detailed understanding of their interaction mechanisms on a cellular level. Therefore, quantification of NP internalization is crucial to predict the potential impact of intracellular NP doses, providing essential information for risk assessment as well as for drug delivery applications. In this study, the internalization of $25 \mathrm{~nm}$ and $85 \mathrm{~nm}$ silica nanoparticles (SNPs) in alveolar type II cells (A549) was quantified by application of super-resolution STED (stimulated emission depletion) microscopy. Cells were exposed to equal particle number concentrations $\left(9.2 \times 10^{10} \mathrm{particles}^{-1}\right)$ of each particle size and the sedimentation of particles during exposure was taken into account. Microscopy images revealed that particles of both sizes entered the cells after $5 \mathrm{~h}$ incubation in serum supplemented and serum-free medium. According to the in vitro sedimentation, diffusion, and dosimetry (ISDD) model $20-27 \%$ of the particles sedimented. In comparison, $10^{2}-10^{3}$ NPs per cell were detected intracellularly serum-containing medium. Furthermore, in the presence of serum, no cytotoxicity was induced by the SNPs. In serum-free medium, large agglomerates of both particle sizes covered the cells whereas only high concentrations $\left(\geq 3.8 \times 10^{12}\right.$ particles $\left.\mathrm{mL}^{-1}\right)$ of the smaller particles induced cytotoxicity.

\section{Introduction}

Engineered nanomaterials (ENMs) are already out on the market and are found in a broad range of applications, ranging from everyday goods to electronics and biomedicine [1]. Examples are filler materials [2], cosmetics [3], and food products [4] as well as polishing agents, capacitors [1], and contrast agents [5]. Beyond that, many ENMs show promise for their use in novel and future applications [6]. In particular, in the biomedical field new ENMs are developed for targeted drug delivery, therapeutic, and theranostic purposes [7]. Considering the numerous fields of application as well as the broad variety of ENM types, it is critical to identify the relevant NP properties contributing to adverse health and environmental effects in order to design safe ENMs. Biologically relevant NP properties are considered to be intrinsic particle properties that might be modulated by interactions with molecules present in the environment.

To understand the mechanisms of NP cell interactions, it is important to identify and quantify NP targets within the body, including the location of internalized NPs on a cellular and subcellular level. NPs seem to enter cells via endocytotic as well as nonendocytotic pathways depending on size, surface chemistry, and shape [8-10]. In addition to physicochemical properties, it was demonstrated that internalization efficiency and particle induced toxicity in vitro depend on the presence of proteins in biological fluids [11]. In a recent study, the influence of the protein corona, associated with particles after dispersion in serum-containing media or biological fluids, on particle uptake has been attributed to a modulation of particle adhesion to the cellular surface $[10,12]$.

The mechanisms of toxicity induced by ENMs on a molecular level are still under investigation and due to a lack in standardization and comparability, in vitro studies apparently produce contradicting results regarding cytotoxic or even more subtle toxic effects. Besides differences in the particle properties, the protein corona, which modulates the cellular response to particles, may also give rise to these inconsistent results [13]. SNPs, for instance, are shown to 
induce reactive oxygen species (ROS) and DNA as well as chromosomal damage in various cell types [14-16]. Other studies demonstrate that SNPs enter cells but induce no cytotoxic or genotoxic effects $[17,18]$. Thus, in order to elucidate how NPs induce specific cellular responses, it is critical to have information not only about administered (the initially added dose) and delivered (particles reaching the cell monolayer via diffusion and sedimentation) doses [19], but also about the cellular (particles associated with the cells) and intracellular doses (particles internalized by the cells). Ultimately, such data is also critical for a proper hazard assessment. For example, Geiser and Kreyling estimated that $1.4 \times$ $10^{11} \mathrm{NPs}$ per day are deposited in the lung, after exposition of a healthy individual to a moderate concentration of $3 \times$ $10^{4}$ ambient particles $\mathrm{cm}^{-3}$ air volume. Even at the highest possible aerosol number concentration, an alveolar cell will maximally receive on average 120 NPs per hour [20]. Usually, during in vitro experiments, submerged cells are exposed to NPs dispersed in media. The diffusion, sedimentation, and agglomeration of these NPs, which are dependent on particle size and surface properties as well as density of the surrounding fluid, then have an impact on the delivered dose [21]. Therefore, Hinderliter et al. proposed a computational model to evaluate the fraction of the delivered dose that is deposited in an in vitro experiment [22].

Different approaches have been utilized to experimentally quantify the cellular or intracellular dose of NPs, such as atomic emission spectrometry [23], laser ablation ICP-MS [24], flow cytometry, imaging flow cytometry, and electron microscopy [25-28]. Of these, only electron microscopy enables direct counting of NPs [29], with the disadvantage of elaborate sample preparation. To quantify NP uptake, flow cytometry is used as a high throughput method. In contrast to this approach, confocal laser scanning microscopy (CLSM) retrieves information about the intracellular NP location. For example, CLSM has been employed to observe fluorescently labeled SNPs in cytosolic vesicles [30, 31]. As per the definition [32], the size range of NPs $(1-100 \mathrm{~nm})$ is below the classical optical resolution limit. Therefore, a promising method to study NP cell interactions is superresolution fluorescence microscopy. Since the early nineties, several techniques have been developed to enhance resolution in optical microscopy. These techniques include (1) methods like 4Pi and $\mathrm{I}^{5} \mathrm{M}[33,34]$, (2) single-molecule localization techniques, (3) structured illumination microscopy (SIM) [35-37], and (4) STED (stimulated emission depletion) microscopy [38]. In the first approaches, dual-beam interference between two opposing objectives is used for axial resolution improvement. Single-molecule localization techniques are based on blinking/switching of fluorophores and include PALM (photoactivated localization microscopy) [39], STORM (stochastic optical reconstruction microscopy) [40], and related methods [41-46]. In SIM, high frequency information of the specimen is transferred to a transmittable lower frequency range, whereas STED microscopy depletes fluorophores in the outer area of the point-spread function to sharpen the focus and, therefore, increases resolution in the lateral and/or axial plane. Using STED microscopy, it was demonstrated that $30 \mathrm{~nm}$ fluorescently labeled SNPs penetrated the nucleus of Caco-2 cells [47]. Using spinning disc and $4 \mathrm{Pi}$ confocal microscopy [33], Jiang et al. assessed the uptake of $8 \mathrm{~nm} \mathrm{D}$-penicillamine-coated quantum dots in live HeLa cells. The authors observed a dose-dependent increase in intracellular, as well as membrane-associated, fluorescence per cell area [48]. Although recently an approach has been described to quantify internalized 1000, 400, and $250 \mathrm{~nm}$ sized polystyrene particles using CLSM in combination with high-throughput FACS data [49], the quantification of absolute numbers of NPs is still a challenge. Optical imaging techniques with enhanced resolution are needed to accurately determine the intracellular delivery of particles smaller than $200 \mathrm{~nm}$ in diameter.

In the present study, we used for the first time STED microscopy image stacks to quantify internalized fluorescently labeled $25 \mathrm{~nm}$ and $85 \mathrm{~nm}$ sized SNPs in A549 cells, as a model for lung epithelial cells. Image segmentation was applied to differentiate between internalized and attached NPs within 3D image stacks of whole cells. Here, the quantification of internalized SNPs is not based on measuring the mean fluorescence intensity of single particles or of cell-associated particles like in other approaches, but on segmented objects. Cells were exposed to identical initial particle concentrations (administered dose) and the intracellular doses were determined. In order to evaluate the role of proteins in NP cell interactions [11, 12], cells were exposed to SNPs in the presence and absence of serum proteins. Furthermore, the cytotoxicity of these SNPs was investigated with regard to the protein content in the surrounding medium.

\section{Material and Methods}

2.1. NP Synthesis and Labeling. All chemicals used for particle synthesis were supplied from Sigma-Aldrich (Taufkirchen, Germany) in the highest purity available. Atto647-NHS ester was purchased from Atto-Tec (Siegen, Germany). All procedures, which involved the active Atto-NHS ester, were performed under exclusion of moisture and light.

SNPs were synthesized as described before [47]. After synthesis, the particles were purified by dialysis against MilliQ water followed by filtration through a sterile $0.2 \mu \mathrm{m}$ membrane. To confirm the complete dye incorporation into the SNPs, a $100 \mu \mathrm{L}$ aliquot was centrifuged through a $30 \mathrm{kDa}$ membrane followed by fluorescence spectroscopy (Spex FluoroMax-3, Horiba Scientific GmbH, Germany).

\subsection{Particle Characterization. A series of TEM micrographs} of dried nanoparticle dispersions obtained by electron microscopy (Philips CM200 FEG, FEI Company, Netherlands) was selected to estimate the average primary particle size. Samples were prepared by immersion of a 200-mesh carbon-coated copper grid into the nanoparticle suspension. Image J software from the National Institutes of Health (http://rsb.info.nih.gov/ij/) was used to estimate the mean particle size and particle size distribution.

Dynamic light scattering (DLS, Dyna Pro Titan, Wyatt Technology Europe $\mathrm{GmbH}$ and Nanotrac-Ultra, Microtrac 
Europe $\mathrm{GmbH}$, Germany) was used to estimate the average hydrodynamic diameter of NPs dispersed in water and in cell culture medium. DLS measurements of $25 \mathrm{~nm}$ particles dispersed in serum-containing medium were not possible because protein and particle signals overlapped.

The zeta potential was measured with a Nanosizer Z (Malvern Instruments, Worcestershire, UK) in water at $150 \mathrm{~V}$ using $10^{-3} \mathrm{M} \mathrm{KCl}$ as background electrolyte. Each sample underwent three series of measurements (with each series comprising 40 measurements). In cell culture medium the zeta potential was measured at $20 \mathrm{~V}$. Analytical centrifugation was performed with a LUMiSizer Dispersion Analyzer (LUM $\mathrm{GmbH}$, Germany) by software controlled centrifugation of $1.4 \mathrm{~mL}$ of the sample dispersion. Size distribution and histograms were calculated using proprietary SEP View 6 software.

The specific surface area of the SNPs used in this study was calculated by comparison with unlabeled SNPs prepared by the same protocol. Briefly, the specific surface area of bare SNPs with a size of 23,35 , and $72 \mathrm{~nm}$ was determined by BET analysis via nitrogen adsorption (Autosorb-6B, Quantachrome Instruments, USA). A simple linear regression model $\left(y=143.2-1.505 x\right.$, with $y=$ surface area $\left[\mathrm{m}^{2} / \mathrm{g}\right]$, $x=$ particle diameter [nm], and $\left.r^{2}=0.999\right)$ was used to extrapolate the BET surface area for Atto647N labeled particles assuming no significant difference in the adsorption behavior and porosity of bare and labeled silica. Nanoparticle number concentrations were calculated based on the EM derived particle diameter and the $\mathrm{SiO}_{2}$ content, which was obtained by ICP-OES (Ultima 2, Horiba JobinYvon, Japan). Endotoxin tests were performed using the LAL Gel Clot Assay (Lonza) according to Kucki 2012 [50].

2.3. Cell Culture. The cell line A549 as model for human alveolar epithelial type II cells was obtained from the German Collection of Microorganisms and Cell Culture (DSMZ, Braunschweig, Germany) and was maintained in a humidified incubator $\left(37^{\circ} \mathrm{C}, 9 \% \mathrm{CO}_{2}\right.$, and $\mathrm{pH}$ 7.4) in Dulbecco's modified Eagle medium (DMEM, Gibco, Life Technologies, USA) supplemented with $10 \%$ fetal bovine serum (FBS, PAN biotech, Germany). After reaching $\sim 80 \%$ confluence, cells were dislodged by using $0.05 \%$ trypsin containing $0.02 \%$ EDTA. For the analysis of particle uptake, A549-pAcGFP1Mem cells were used as described in Schumann et al. 2012 [30]. These cells express a green fluorescent protein derivative fused to the $\mathrm{N}$-terminal membrane targeting signal of neuromodulin for membrane labeling (Clontech, Mountain View, CA). A549-pAcGFP1-Mem cells were maintained in selective cell culture medium (DMEM with 10\% FBS) containing $200 \mu \mathrm{g} \mathrm{mL}^{-1} \mathrm{G} 418$.

2.4. Exposure of Cells to NPs. For confocal imaging, A549pAcGFP1-Mem cells were seeded on glass coverslips at a density of $1 \times 10^{5}$ cells $\mathrm{mL}^{-1}$ in 12 -well plates (Greiner BioOne, Frickenhausen, Germany) and allowed to attach for at least $20 \mathrm{~h}$. Nanoparticle dispersions were freshly prepared in serum-free or serum-containing medium. Exposure time for all experiments was 5 hours, unless otherwise stated. Cells were incubated with Si-25-FD and Si-85-FD dispersions at a concentration of $9.2 \times 10^{10}$ particles $\mathrm{mL}^{-1}$. For scanning electron microscopy, $1 \times 10^{5}$ cells $\mathrm{mL}^{-1}$ were incubated on glass coverslips in 12 -well plates with 1,10 , and $100 \mu \mathrm{g} \mathrm{mL}^{-1}$ unlabeled SNPs in presence and absence of serum. For cytotoxicity experiments, A549 cells were seeded in 96well plates at a density of $1 \times 10^{5}$ cells $\mathrm{mL}^{-1}$. Here, particle dispersions of $\mathrm{Si}-25$ and $\mathrm{Si}-85$ at concentrations of 1, 10, 50 , and $200 \mu \mathrm{g} \mathrm{mL}^{-1}$ were used. Control samples were not exposed to NPs.

2.5. Immunostaining. After the incubation, cells were washed two times with DPBS, fixed with $4 \%$ paraformaldehyde in PBS for $30 \mathrm{~min}$, and permeabilized with $0.2 \%$ Triton X-100 for $15 \mathrm{~min}$ at room temperature. Lamin-B (goat polyclonal antibody, sc-6216, Santa Cruz, Heidelberg, Germany) and secondary antibody Alexa Fluor 546 (donkey anti-goat, A11056, Invitrogen, Darmstadt, Germany) were used to stain the lamina of the nucleus. Cells were mounted on glass slides with Mowiol/DABCO (Sigma Aldrich, Taufkirchen, Germany).

2.6. STED and Confocal Microscopy. A confocal laser scanning microscope Leica TCS-SP5 STED (Leica Microsystems, Mannheim, Germany) with a Leica HCX PLAN APO $100 \mathrm{x} / 1.4$ oil immersion objective was used. Specimens were imaged using the $488 \mathrm{~nm}$ laser line of an Argon laser for excitation of the cellular membrane label (AcGFP1) and a $561 \mathrm{~nm}$ DPSS laser for excitation of the nuclear membrane label (Alexa Fluor 546). Cellular structures were imaged in confocal mode. The NPs, labeled with Atto647N, were imaged in STED mode (after incubation of cells in presence of serum) using a pulsed $635 \mathrm{~nm}$ laser diode (PicoQuant, Berlin, Germany) for excitation and an infrared laser (MaiTai, Spectra Physics, Santa Clara, United States) running at $750 \mathrm{~nm}$ for STED depletion. After incubation of cells in absence of serum, Atto647N labeled particles were imaged in confocal mode using the pulsed $635 \mathrm{~nm}$ laser diode for excitation. APD modules (Perkin-Elmer SPCM-AQRH) were used for detection of particle signals received in STED mode, whereas cellular structures and particle signals received in confocal mode were detected with the internal analog PMT detectors. The confocal pinhole was set to $1 \mathrm{AU}$ to optimize zsectioning. Images and $\mathrm{z}$-stacks were recorded sequentially. A step size of $130 \mathrm{~nm}$ was chosen. The pixel size was set to $30 \mathrm{~nm}$ for STED and $60 \mathrm{~nm}$ for confocal images to avoid undersampling. To determine the $3 \mathrm{D}$ experimental pointspread function (PSF) of the system, $40 \mathrm{~nm}$ dark red fluorescent beads (F8789, Invitrogen) were imaged in STED mode, and $100 \mathrm{~nm}$ fluorescent multicolor beads (T7279, Invitrogen) were used for conventional confocal imaging. The full width at half maximum (FWHM) of the experimental PSF in the focal plane, as indicator for the lateral resolution, was $76 \mathrm{~nm}$ in STED mode and $277 \mathrm{~nm}$ in diffraction-limited confocal mode.

2.7. Image Processing. STED and confocal data were deconvolved using an iterative maximum likelihood algorithm 
implemented in Huygens Professional (SVI, Hilversum, Netherlands) and experimentally (for confocal mode) or theoretically (for STED mode) determined PSFs.

To discriminate between NPs inside and outside the cell the "Surface Renderer" tool of the Huygens software was used. The position of the isosurface was set at an intensity threshold calculated by the Otsu algorithm [51]. Thereby retrieved 3D region was set as region of interest (ROI). Remaining holes in the isosurface were closed with an open-close algorithm with a voxel number of two. To extend the ROI to the whole cell, the implemented "fill inner and cutoff cavities" algorithm was applied. If several cells were imaged in one frame, the segmented objects were additionally chosen by a manually drawn mask. In the NP channel, after the Otsu-thresholding, a watershed segmentation with a sigma of $2.0 \mu \mathrm{m}$ for the beforehand Gaussian filter was used to separate small NP agglomerates. Objects below an intensity value of $5 \%$ of the range between threshold and intensity maximum were discarded. All in this manner segmented objects of the NP channel inside the ROI of the cell were counted. The image processing workflow is illustrated in Figure 10.

\subsection{Sedimentation, Diffusion, and Dosimetry Model (ISDD)} Simulations. To investigate the effect of sedimentation and diffusion on the SNPs used in this study and to determine the delivered dose, the ISDD model, presented by Hinderliter et al. [22], was applied. The following parameters were applied: the $\mathrm{SiO}_{2}$ mass concentration was $1.2 \mu \mathrm{g} \mathrm{SiO} \mathrm{mL}^{-1}(25 \mathrm{~nm}$ SNPs) and $50 \mu \mathrm{g} \mathrm{SiO}_{2} \mathrm{~mL}^{-1}$ (85 $\mathrm{nm} \mathrm{SNPs),} \mathrm{corresponding} \mathrm{to}$ the used particle number concentration of $9.2 \times 10^{10} \mathrm{~mL}^{-1}$. A density of $1.8 \mathrm{~g} \mathrm{~cm}^{-3}$ was assumed for the SNPs. The number of particles per agglomerate was set to 1 and additionally to 3 or 4 particles per cluster. Other input parameters were the height of the medium column above the cells $(5 \mathrm{~mm}$, measured), its volume $(1 \mathrm{~mL})$, the temperature $\left(37^{\circ} \mathrm{C}\right)$, and the deposition time $(5 \mathrm{~h})$.

2.9. Scanning Electron Microscopy of A549 Cells. After incubation, cells were fixed with $2.5 \%$ glutaraldehyde for $30 \mathrm{~min}$ at room temperature and rapidly dehydrated in a graded ethanol series and hexamethyldisilazane (HMDS). Samples were gold-palladium coated for high vacuum mode imaging and analyzed with an ESEM Quanta 400 FEG (FEI Company, Hillsboro, USA) microscope.

2.10. Membrane Integrity ( $L D H$ Assay). The activity of lactate dehydrogenase (LDH) in the cell culture medium as an indicator for cell membrane damage after treatment with SNPs was measured using the CytoTox-ONE Homogenous Membrane Integrity Assay kit (Promega) according to the manufacturers' instructions. Cells incubated with medium only were used as negative controls and cells treated with Triton-X 100 were used as positive controls. A no cell control was included to measure the background fluorescence of the culture medium. After particle exposure, medium $(50 \mu \mathrm{L})$ from each well was placed in a black 96-well plate and $50 \mu \mathrm{L}$ CytoTox-ONE reagent was added and incubated for $10 \mathrm{~min}$ in the dark. Fluorescence was measured at excitation and emission wavelengths of $560 \mathrm{~nm}$ and $590 \mathrm{~nm}$ with a Tecan Microplate reader (Molecular Devices). Interference of the used SNPs with the assay was excluded prior to analysis by measuring the fluorescence of Triton-X-100 lysed cells in presence of $200 \mu \mathrm{g} \mathrm{mL}^{-1}$ SNPs. No changes in the fluorescence signals could be observed. At $590 \mathrm{~nm}$ the SNPs do not absorb light.

2.11. Statistics. Results are presented as means and standard deviation (SD). Statistical comparisons were made with unpaired Student's $t$-test at a 95\% confidence level. Differences in the viability of A549 cells were considered significant at $p<0.05$.

\section{Results}

3.1. Physicochemical Properties of SNPs. In this study, cells were exposed to amorphous SNPs with diameters of $25 \mathrm{~nm}$ (Si-25) and $85 \mathrm{~nm}$ (Si-85). For microscopy analysis and subsequent quantification, the NPs were fluorescently labeled using Atto647N (Si-25-FD and Si-85-FD, resp.). The physicochemical properties of the particles are shown in Table 1. The mean particle diameters as determined from TEM micrographs were $25 \pm 3 \mathrm{~nm}$ (Si-25), $24 \pm 2 \mathrm{~nm}$ (Si-25-FD), $84 \pm 7 \mathrm{~nm}$ (Si-85), and $85 \pm 8 \mathrm{~nm}$ (Si-85-FD), respectively. The hydrodynamic diameter of each type of particle dispersed in water or serum-free medium (Dulbecco's modified Eagle medium (DMEM)) was found to be comparable to its corresponding mean particle diameter, determined by EM. The diameter of $25 \mathrm{~nm}$ particles dispersed in serum-containing medium (DMEM + 10\% FBS) could not be measured due to significant interference signals of medium proteins. Therefore, concentration-dependent particle stability in serumcontaining media was measured using $94 \mathrm{~nm}$ SNPs (see Additional file 1 in Supplementary Material available online at http://dx.doi.org/10.1155/2015/961208).

All particles exhibited a negative zeta potential in all of the three media measured (Table 1). However, in the presence of serum-free and complete culture medium a reduction of the absolute zeta potential values was observed. The specific surface area of $25 \mathrm{~nm}$ particles was calculated to be almost three times larger than the specific surface area of $85 \mathrm{~nm}$ particles. No endotoxin contamination was detected in dispersions of $\mathrm{Si}-25$ and $\mathrm{Si}-85$ particles.

3.2. Simulation of NP Sedimentation and Diffusion. In this study, cells were grown in a standard submersed cell culture system and then exposed to NPs by exchange of the medium with NP-containing medium. The initial concentration (administered dose) of Si-25-FD and Si-85-FD was $9.2 \times$ $10^{10}$ particles $\mathrm{mL}^{-1}$, respectively. Since it is known that NPs reach the cell surface by sedimentation and diffusion, which depend on the particle size, the delivered dose was simulated by using the ISDD model for noninteracting spherical particles and their agglomerates presented by Hinderliter et al. [22]. The model is based on Stokes' law, which predicts particle sedimentation velocity, and the Stokes-Einstein equation, which describes the diffusion coefficient of the particles. 
TABLE 1: Physicochemical properties of SNPs used in the study.

\begin{tabular}{lccccccc}
\hline \multirow{2}{*}{ Sample } & \multirow{2}{*}{ Diameter EM [nm] } & \multicolumn{2}{c}{ Hydrodynamic diameter $[\mathrm{nm}]$} & \multicolumn{3}{c}{ Zeta potential [mV] } & \multicolumn{2}{c}{${\text { BET surface area [m }{ }^{2} \mathrm{~g}^{-1} \text { ] }}^{2}$} \\
& & Water & DMEM & Water & DMEM & DMEM + 10\% FBS & 106 \\
\hline Si-25 & $25 \pm 3$ & $21 \pm 3$ & $28 \pm 13$ & -24 & $-17 \pm 4$ & $-3 \pm 2$ & 37 \\
Si-85 & $84 \pm 7$ & $71 \pm 15$ & $86 \pm 16$ & -42 & $-21 \pm 2$ & $-14 \pm 4$ & 108 \\
Si-25-FD & $24 \pm 2$ & $24 \pm 4$ & $35 \pm 8$ & -31 & $-5 \pm 3$ & $-8 \pm 2$ & 37 \\
Si-85-FD & $85 \pm 8$ & $79 \pm 18$ & $77 \pm 15$ & -38 & $-30 \pm 2$ & $-7 \pm 4$ & \\
\hline
\end{tabular}

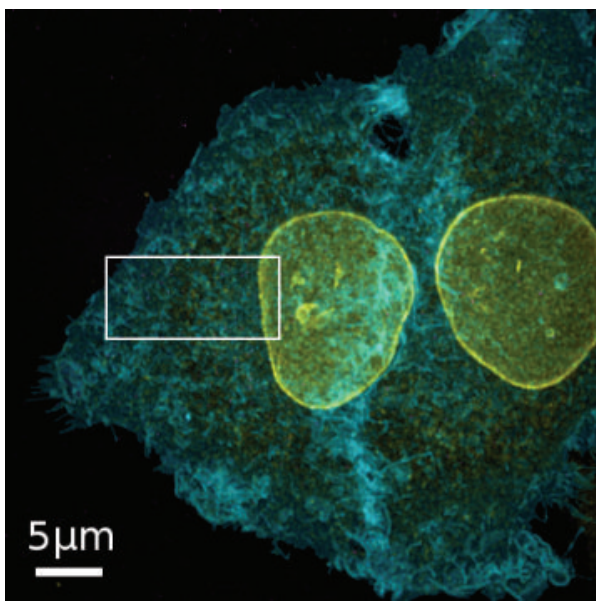

(a)

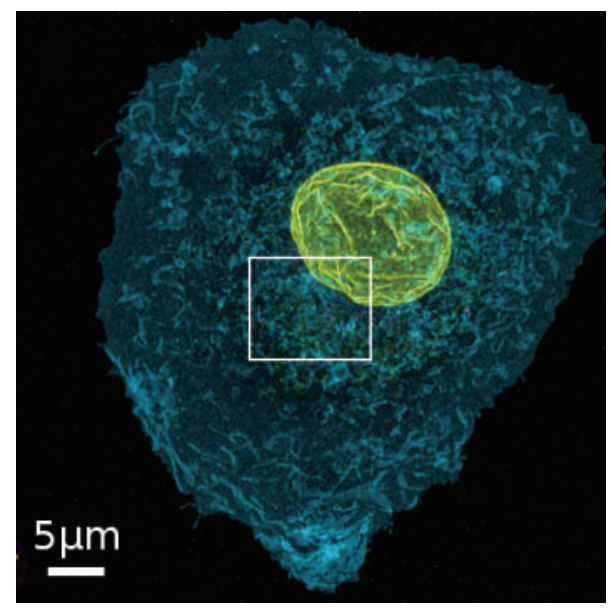

(b)

FIGURE 1: Overviews of A549 cells exposed to SNPs. Images are maximum intensity projections obtained by taking z-stacks of whole A549 cells that had been exposed to Si-25-FD (a) or Si-85-FD (b) particles at an initial number concentration of $9.2 \times 10^{10} \mathrm{SNPs}_{\mathrm{mL}}^{-1}$ for $5 \mathrm{~h}$. For microscopy studies, A549-pAcGFP1-Mem cells were used, expressing a fluorescent protein derivative fused to the $N$-terminal membrane targeting signal of neuromodulin for membrane labeling (cyan). The nuclear lamina is shown in yellow. SNPs (magenta), labeled with Atto647N, were imaged in STED mode and the two other structures in conventional confocal mode. White boxes indicate the areas shown in more detail in Figures 2 and 3. Contrast and brightness were adjusted in all images for better illustration.

The delivered dose in serum-containing medium was calculated assuming a cluster size of one, according to the DLS analysis (Table 1), and taking into account the stabilizing effects of serum [52]. The simulation revealed that after $5 \mathrm{~h}$ the number fraction of deposited particles was $26.5 \%$ and $20.4 \%$ for Si-25 and Si-85 particles, respectively (Table 2 ).

3.3. Uptake of SNPs in the Presence and Absence of Serum. In order to determine the uptake of fluorescently labeled SNPs, A549 cells expressing a green fluorescent protein targeted to the cytoplasmic membrane (A549-pAcGFP1-Mem) were exposed to $9.2 \times 10^{10} \mathrm{SNPs} \mathrm{mL}^{-1}$ in complete or serumfree medium for $5 \mathrm{~h}$. This exposure time was chosen because a significant amount of particles was expected to become internalized by that time [17]. In the two example overviews of cells exposed to particles in serum supplemented medium (Figure 1), only the cellular structures imaged in confocal mode can be seen. Nevertheless, the STED signals of the particles were recorded during image analysis. Enlarged sections of the cells depicted in Figure 1 are shown in Figures 2 and 3. In these sections, the NPs imaged in STED mode are clearly visible. The particles appeared to be distributed throughout the cells. No large particle agglomerates were detected inside or outside of the cells (Figures 2 and 3). A fluorescence intensity plot of a sample $25 \mathrm{~nm}$ particle (Figure 2, yellow line) within the cell revealed a full width of half maximum (FWHM) of $61 \pm 4 \mathrm{~nm}$ (the error corresponds to the standard deviation of Gaussian fit). This value was lower than the mean FWHM of the point-spread function that had been obtained by measurements using fluorescently labeled $(40 \mathrm{~nm})$ latex beads $\left(\mathrm{PSF}_{\mathrm{STED}} \approx 76 \mathrm{~nm}\right.$ ). On the other hand, the FWHM determined by STED imaging was two-times larger than the particle diameter determined by TEM. In contrast, an intensity plot through an exemplary $85 \mathrm{~nm}$ particle (Figure 3, yellow line) resulted in a FWHM of $88 \pm 4 \mathrm{~nm}$ (error: standard deviation of Gaussian fit), corresponding to the particle diameter determined by TEM. In both cases, particle size values measured by STED imaging were well below the classical optical resolution limit. Although STED imaging did not allow single $25 \mathrm{~nm}$ particles to be resolved, single $85 \mathrm{~nm}$ particles were clearly resolved.

After exposition of A549 cells to either $25 \mathrm{~nm}$ or $85 \mathrm{~nm}$ SNPs in absence of serum, large (up to a few $\mu \mathrm{m}$ in size), irregular particle agglomerates were observed (Figures 4 and 5). In contrast, DLS measurements did not indicate formation of agglomerates under these conditions (Table 1). The brightness of these agglomerates saturated the avalanche 


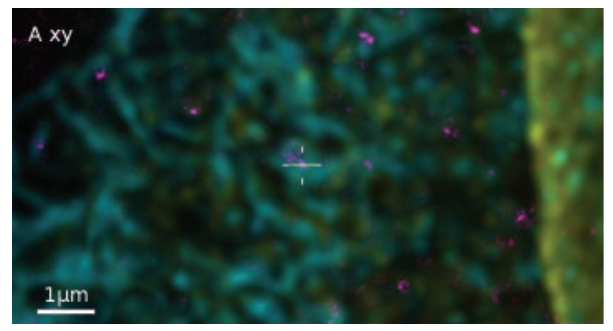

(a)

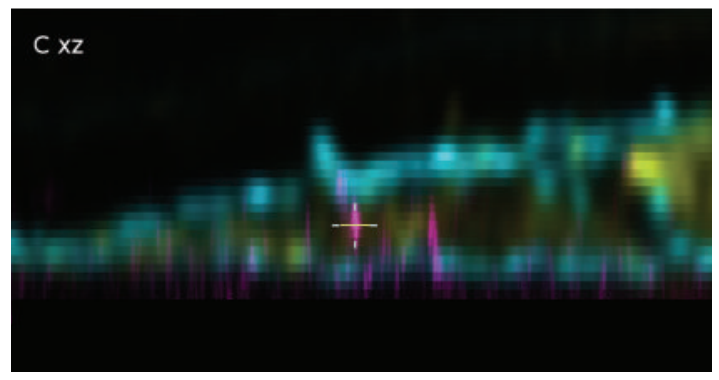

(c)

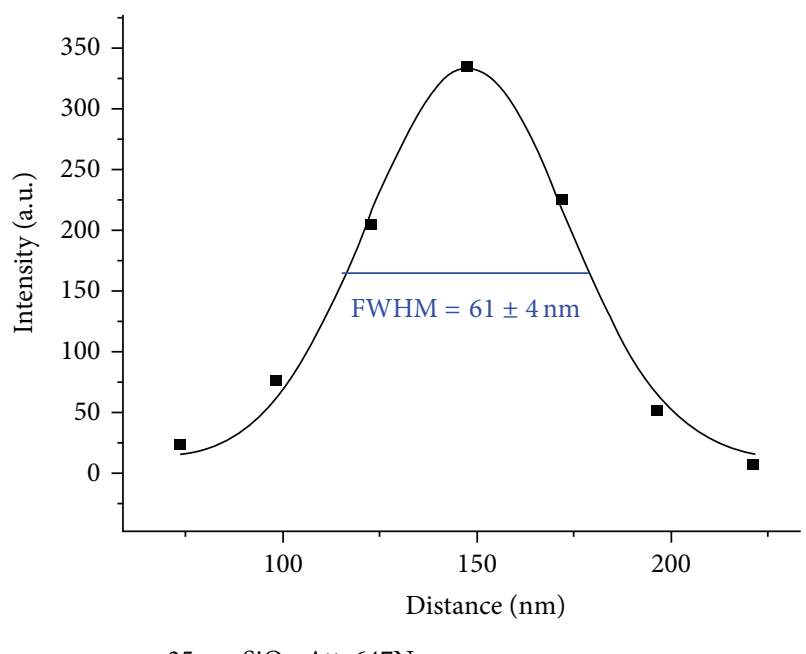

- $25 \mathrm{~nm} \mathrm{SiO} 2-$ Atto647N Gaussfit

(b)

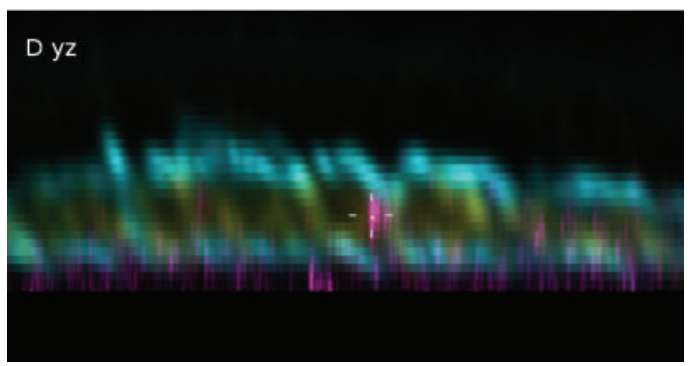

(d)

FIgURE 2: Enlarged sections of an A549 cell exposed to Si-25-FD particles for $5 \mathrm{~h}$. ((a), (c), and (d)) They are orthogonal sections of the area indicated in Figure 1(a). Intersecting planes pass the middle of the image (cross hair). SNPs (magenta), membrane (cyan), and nuclear lamina (yellow). (b) An intensity plot through a sample nanoparticle (yellow line) within the cell. The full width of half maximum (FWHM) was 61 $\pm 4 \mathrm{~nm}$, which is well below the classical optical resolution limit (error: standard deviation of Gaussian fit).

TABLE 2: Sedimentation and diffusion simulation results.

\begin{tabular}{|c|c|c|c|c|c|c|}
\hline \multirow{3}{*}{$\begin{array}{l}\text { Particles/cluster } \\
\text { Particle diameter }\end{array}$} & \multicolumn{6}{|c|}{ Deposited } \\
\hline & \multicolumn{2}{|c|}{1} & \multicolumn{2}{|c|}{3} & \multicolumn{2}{|c|}{4} \\
\hline & Fraction (\%) & $\begin{array}{l}\text { Particle number } \\
\left(\mathrm{cm}^{-2}\right)\end{array}$ & Fraction (\%) & $\begin{array}{l}\text { Particle number } \\
\left(\mathrm{cm}^{-2}\right)\end{array}$ & Fraction (\%) & $\begin{array}{l}\text { Particle number } \\
\left(\mathrm{cm}^{-2}\right)\end{array}$ \\
\hline $25 \mathrm{~nm}$ & 26.5 & $1.22 E 10$ & 19.4 & $8.92 E 9$ & 18.3 & $8.43 E 9$ \\
\hline $85 \mathrm{~nm}$ & 20.4 & $9.40 E 9$ & 21.3 & $9.78 E 9$ & 20.8 & $9.56 E 9$ \\
\hline
\end{tabular}

Results of the ISDD sedimentation model for SNPs with two different diameters ( 25 and $85 \mathrm{~nm}$ ) in $1 \mathrm{~mL}$ solution with a mass concentration corresponding to $9.2 \times 10^{10}$ particles $\mathrm{mL}^{-1}$. Simulation results for deposited particles are given as fraction of delivered particles (\%) and particle number of deposited particles per $\mathrm{cm}^{2}$. The number of deposited particles displays little dependency on the number of particles per cluster for small cluster sizes and is in the same range for both particle sizes.

photodiode (APD) used for detection of the particle fluorescence signals in STED mode, resulting in the automatic power-down of the APD. Therefore, confocal microscopy had to be employed to acquire the image stacks instead. Orthogonal sections of confocal image stacks revealed that micrometer-sized NP agglomerates were only detected outside of the cells. These agglomerates appeared to be tightly attached to the cytoplasmic membrane. Under serum-free conditions the particles also exhibited a high tendency to attach to the surface of the coverslips. These attached particles were not removed by washing steps during sample preparation. Nevertheless, fluorescence signals were also detected inside the lumen of A549 cells, resembling either single particles or small particle agglomerates. Neither in presence nor in absence of serum were NP signals detected in the cell nucleus.

3.4. Quantification of SNP Internalization. The confocal images indicated that, in absence of serum, the SNPs tended to form agglomerates. As stated above, in confocal 

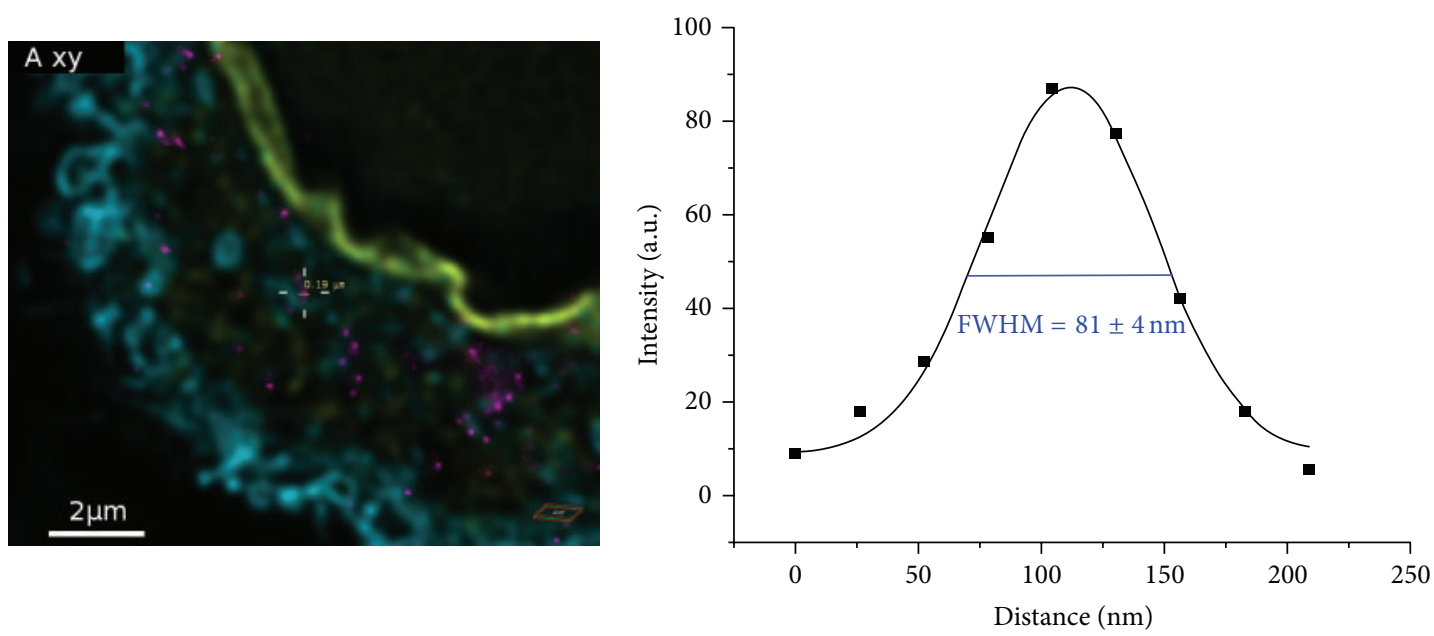

- $85 \mathrm{~nm} \mathrm{SiO}_{2}$-Atto647N

- Gaussfit

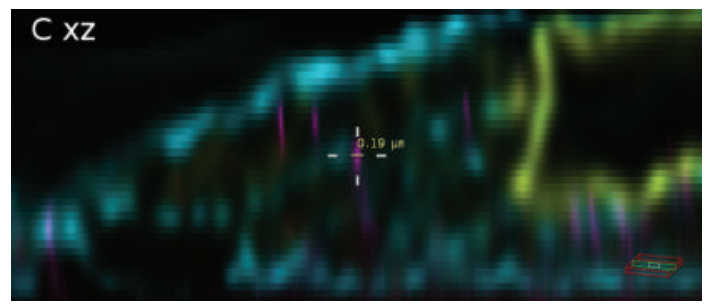

(c) (b)

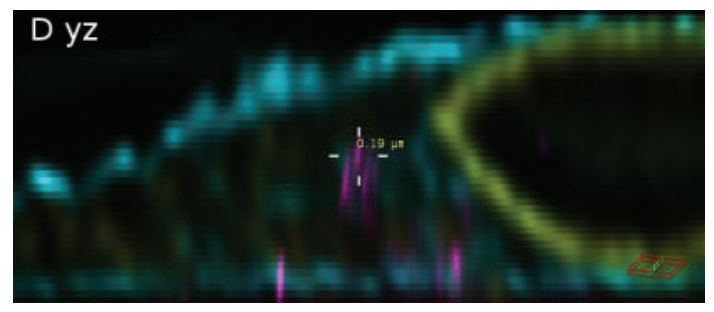

(d)

FIGURE 3: Enlarged sections of an A549 cell exposed to Si-85-FD particles for $5 \mathrm{~h}$. ((a), (c), and (d)) They are orthogonal views of the area indicated in Figure 1(b). Intersecting planes pass the middle of the image (cross hair). SNPs (magenta), membrane (cyan), nuclear lamina (yellow). (b) is an intensity plot through an example nanoparticle (yellow line). The full width of half maximum (FWHM) was $81 \pm 4 \mathrm{~nm}$, indicating that single NPs can be detected in the cytosol (error: standard deviation of Gaussian fit).

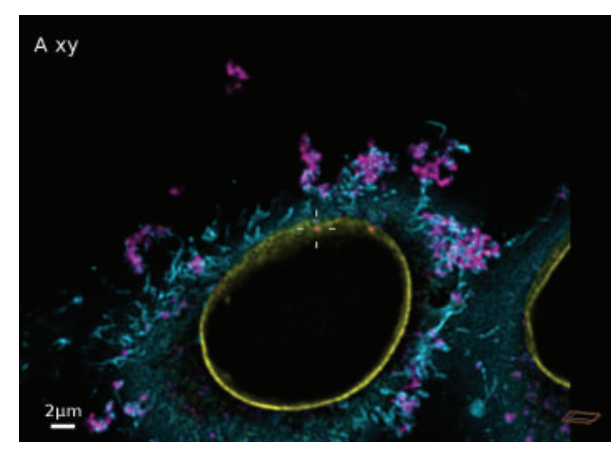

(a)

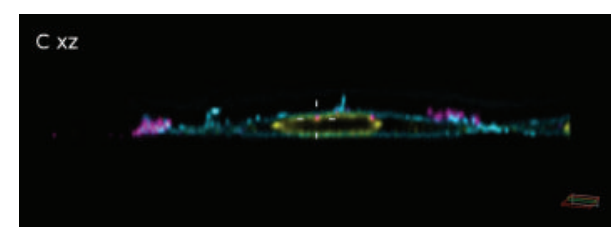

(c)

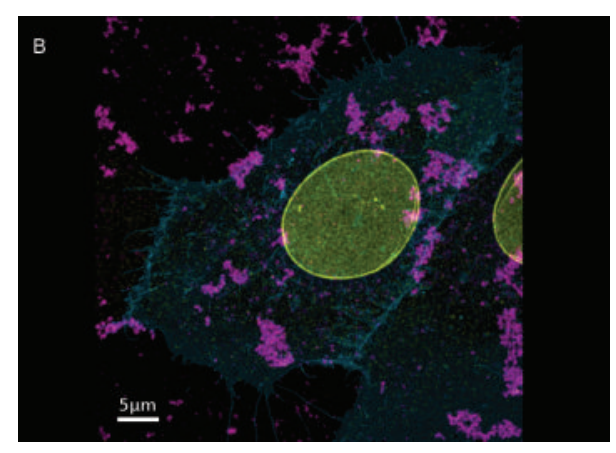

(b)

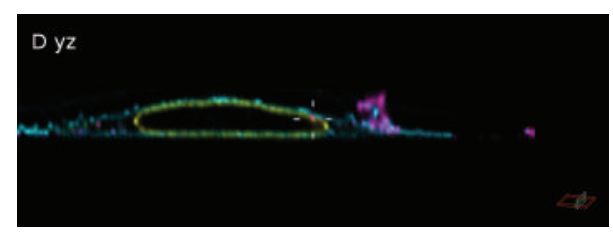

(d)

Figure 4: Confocal images of A549 cells exposed to Si-25-FD particles in the absence of serum. Maximum intensity projection (b) and orthogonal views $(x y, x z$, and $y z)$ of one cell within the same section ((a), (c), and (d)). Intersecting planes pass the middle of the image (cross hair). SNPs (magenta), membrane (cyan), and nuclear lamina (yellow). 


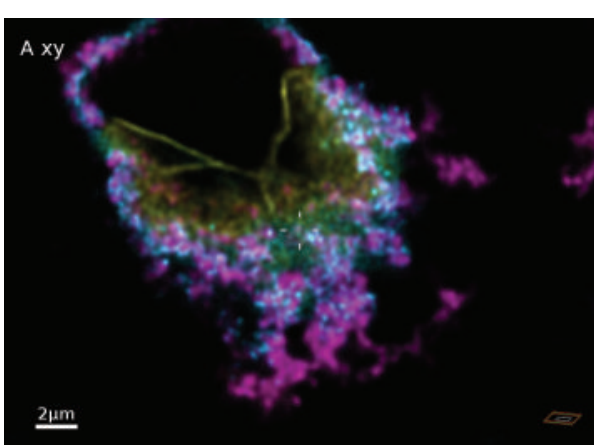

(a)

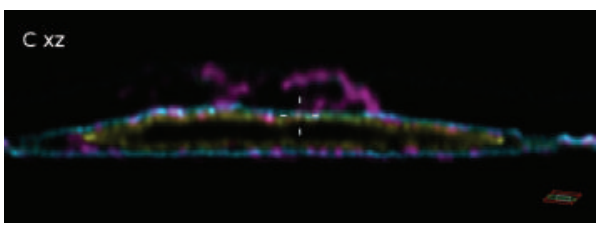

(c)

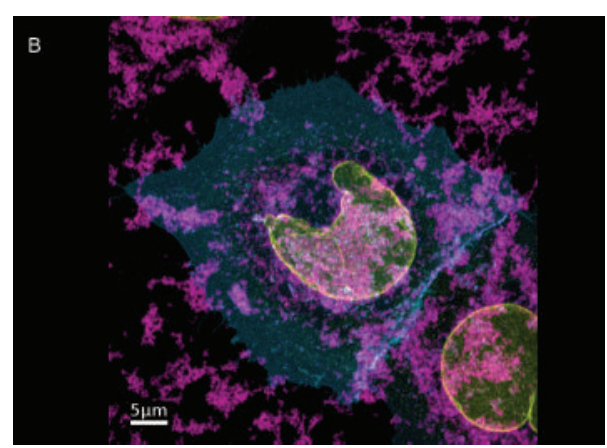

(b)

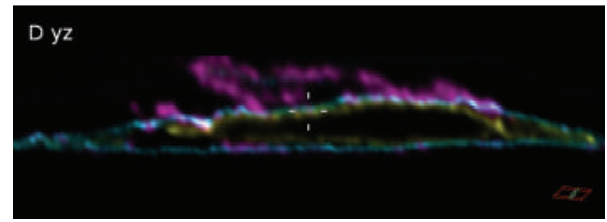

(d)

Figure 5: Confocal images of A549 cells exposed to Si-85-FD particles in the absence of serum. Maximum intensity projection (b) and orthogonal views $(x y, x z$, and $y z)$ of one cell within that image section ((a), (c), and (d)). Intersecting planes pass the middle of the image (cross hair). SNPs (magenta), membrane (cyan), and nuclear lamina (yellow).

TABLE 3: Quantification of internalized SNP.

\begin{tabular}{lccccc}
\hline & Number of objects/cell & Number of objects/cell area $\left(\mu \mathrm{m}^{-2}\right)$ & Number of cells & Total number of objects & Mean intensity (a.u.) \\
\hline Si-25-FD & $117 \pm 126$ & $0.1 \pm 0.1$ & 21 & 2465 & $3.0 E 10 \pm 9 E 3$ \\
Si-85-FD & $338 \pm 171$ & $0.3 \pm 0.2$ & 17 & 5742 & $4.7 E 10 \pm 8 E 3$ \\
\hline
\end{tabular}

Internalized SNPs were quantified by image segmentation of 3D stacks of whole A549 cells. The number of segmented objects in the NP channel is given per cell and per cell area. Also specified is the number of analyzed cells, the total number of objects found in all cells, and the mean fluorescence intensity (arbitrary units) of the objects. After exposition of cells to larger particles, a slightly higher number of objects were found inside the cells. The mean intensity values reflect the stronger fluorescence of the larger particles.

microscopy the fluorescence of the agglomerates saturated the APD detectors. Furthermore, a compensatory reduction of the intensity of the excitation laser caused the fluorescence of single NPs to drop below background. Therefore, only data from cells exposed to NPs in the presence of serum were used for quantification of particle internalization. Segmentation of the corresponding image data for quantification was performed as described in Material and Methods. Quantitative results of SNP internalization obtained by image processing are listed in Table 3. Approximately twenty cells were used to quantify the number of internalized particles at each particle size. After the A549 cells were exposed to either $25 \mathrm{~nm}$ particles or $85 \mathrm{~nm}$ particles, $117 \pm 126$ objects per cell or $338 \pm 171$ objects per cell were detected, respectively. The large deviations in the number of objects can be related to differences in cell size (Additional file 2). The measured difference in the number of objects per cell was found to be statistically significant $(p<0.001)$. In Table 3 the number of objects is also given per cell area. These values also indicate that a greater number of the larger particles were internalized by the cells. Nevertheless, after exposition to both particle sizes, the number of objects per cell was of the same order of magnitude. The mean intensity values of the segmented objects indicate that the objects corresponding to $85 \mathrm{~nm}$ particles exhibited a higher fluorescence intensity compared to the $25 \mathrm{~nm}$ particles. For $25 \mathrm{~nm}$ particles a maximum dye content of 11 molecules per particle was calculated, which is 600 times less than the maximum dye content of 6690 molecules per particle, calculated for $85 \mathrm{~nm}$ particles. Since these are theoretical calculations under the assumption of $100 \%$ coupling yield without considering quenching effects, a smaller difference of fluorescence intensity between the two particle sizes can be expected. Detailed information on microscopy data is given in Additional file 2.

3.5. Influence of Particle Exposure on Cell Morphology. Exposition of A549 cells to $9.2 \times 10^{10}$ particles $\mathrm{mL}^{-1}$, corresponding to mass concentrations of $1.2 \mu \mathrm{g} \mathrm{SiO}_{2} \mathrm{~mL}^{-1}$ ( $25 \mathrm{~nm} \mathrm{SNPs)}$ and $50 \mu \mathrm{g} \mathrm{SiO}_{2} \mathrm{~mL}^{-1}$ ( $85 \mathrm{~nm} \mathrm{SNPs}$ ), was not found to exert a detectable influence on cell morphology, regardless of the medium composition (Figures 1, 4, and 5). This finding was further analyzed by scanning electron microscopy (SEM), including lower and higher NP concentrations. SEM micrographs of cells exposed to either of both particle sizes in complete medium showed that cells underwent no change in cell morphology compared to untreated cells, regardless of the $\mathrm{SiO}_{2}$ concentrations employed $\left(1 \mu \mathrm{g} \mathrm{mL}^{-1}, 10 \mu \mathrm{g} \mathrm{mL}^{-1}\right.$, 

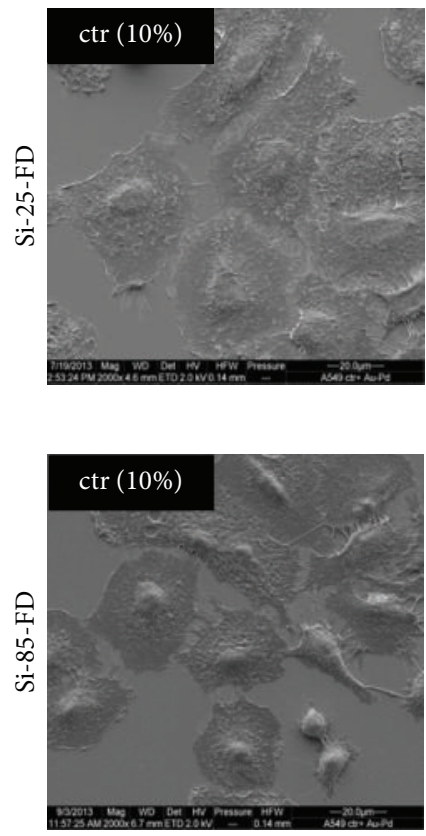
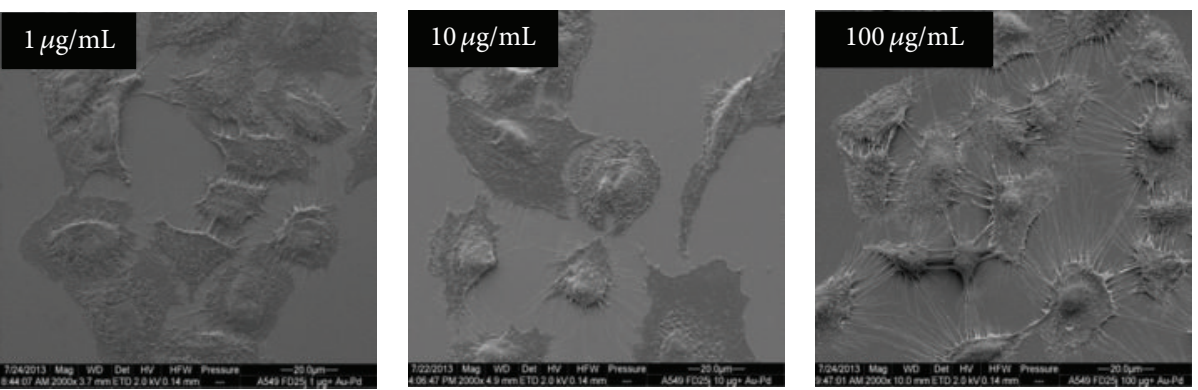

(a)
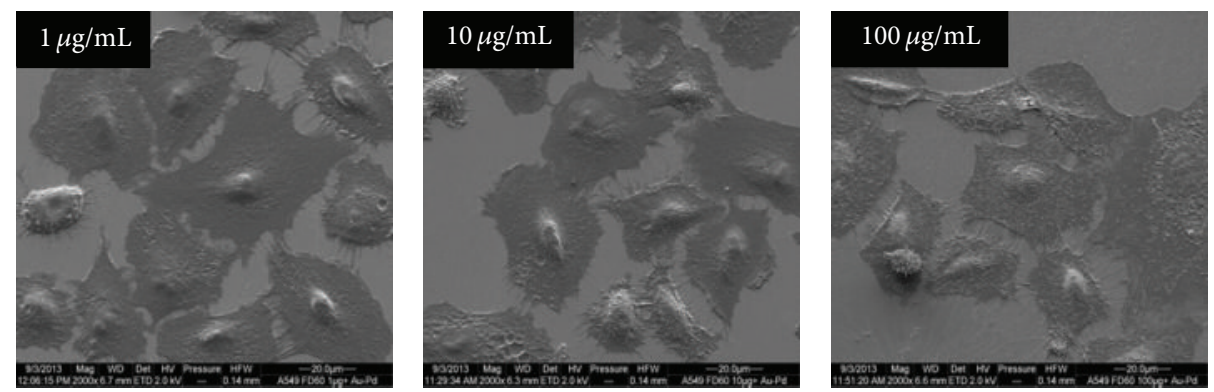

(b)

FIGURE 6: SEM micrographs of human type II alveolar epithelial cells (A549) incubated with Si-25-FD and Si-85-FD in serum-containing medium. No change in cell morphology was observed after exposure to 1,10 , or $100 \mu \mathrm{g} \mathrm{mL}^{-1} \mathrm{SNPs}$ for $5 \mathrm{~h}$. Untreated cells serve as controls (ctr).

and $100 \mu \mathrm{g} \mathrm{mL}^{-1} \mathrm{SiO}_{2}$ ) (Figures 6(a) and 6(b)). Similarly, after cells were exposed to 1 and $10 \mu \mathrm{g} \mathrm{SiO}_{2} \mathrm{~mL}^{-1}$ in serum-free medium, SEM micrographs showed that cell morphology was not affected compared to untreated cells (Figures 7(a) and 7 (b)). However, after exposing cells to $100 \mu \mathrm{g} \mathrm{mL}^{-1}$ of Si25-FD in serum-free medium, the cells appeared rounded. In contrast, after cell exposure to $100 \mu \mathrm{g} \mathrm{mL}^{-1}$ of Si-85-FD under the same conditions, cell morphology did not change, although cells were highly decorated with particle agglomerates.

3.6. Particle Effects on Membrane Integrity. Confocal images as well as SEM micrographs indicated that particles adhered to the cell membrane, especially in absence of serum. Therefore, the effect of SNPs on membrane integrity was analyzed using the lactate dehydrogenase (LDH) assay. After the incubation of A549 cells in presence of 1, 10,50, or $200 \mu \mathrm{g} \mathrm{mL}^{-1}$ of Si- 25 or Si-85 particles in complete medium, no membrane damage was detected (Figure 8). In serumfree medium, only at the highest concentration of $\mathrm{Si}-25$ particles $\left(200 \mu \mathrm{g} \mathrm{m}^{-1}\right)$, an increase in LDH activity was measured (Figure 9). In this case, about $90 \%$ of the cells exhibited LDH leakage. In contrast, membrane damage was not observed after incubation of cells in presence of $200 \mu \mathrm{g} \mathrm{mL}{ }^{-1} \mathrm{Si}-85$ particles dispersed in serum-free medium. Thus, at the particle concentration applied to microscopy analysis, no cytotoxicity was induced. Membrane damage was only observed in absence of serum at particle concentrations greater than $3.8 \times 10^{12} 25 \mathrm{~nm}$ particles $\mathrm{mL}^{-1}$.

\section{Discussion}

Determining the NP dose cells receive during exposure to NPs in vitro and in vivo is essential in order to interpret biological responses with regard to assessing the risk of ENMs and evaluating drug delivery efficiency. Depending on the particle properties, various techniques have been employed to determine the cellular or even intracellular dose. In the present study, A549 cells were exposed to well-defined fluorescently labeled 25 and $85 \mathrm{~nm}$ amorphous SNPs in order to quantify internalized particles. NP quantification was achieved by processing 3D microscopy image stacks. Since the diffraction-limited resolution of CLSM is not sufficient to study the number of NPs inside cells [53], we imaged SNPs using STED microscopy. Furthermore, STED has been demonstrated to provide detailed information about the intracellular distribution and agglomeration state of $130 \mathrm{~nm}$ silica particles and $25 \mathrm{~nm}$ and $85 \mathrm{~nm}$ SNPs [17, 47]. In addition, the detection of individual silica particles by STED has been proven by a correlative STED SEM approach [17].

4.1. Particle Internalization Efficiency. After exposing A549 cells to $25 \mathrm{~nm}$ or $85 \mathrm{~nm}$ particles at $9.2 \times 10^{10} \mathrm{SNPs} \mathrm{mL}^{-1}$ for $5 \mathrm{~h}$, approximately $10^{2}$ objects were detected intracellularly. Analysis of the lateral object widths found within cells treated with $85 \mathrm{~nm}$ particles revealed that single $85 \mathrm{~nm}$ particles could be resolved by STED analysis (Additional file 3b). Additionally, $90 \%$ of the detected objects had a lateral object width of less than $150 \mathrm{~nm}$ and were considered to represent separated particles. Objects with a lateral width of more than 

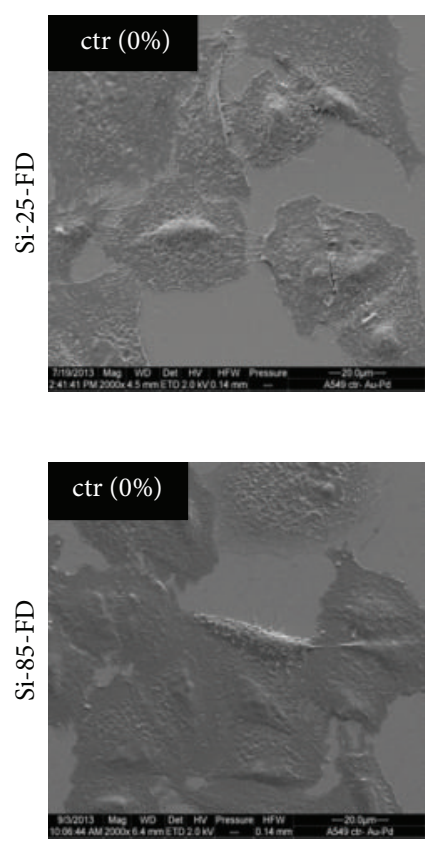
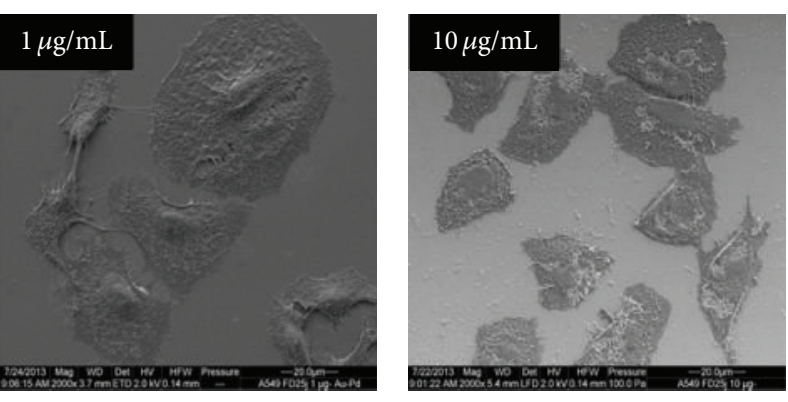

(a)
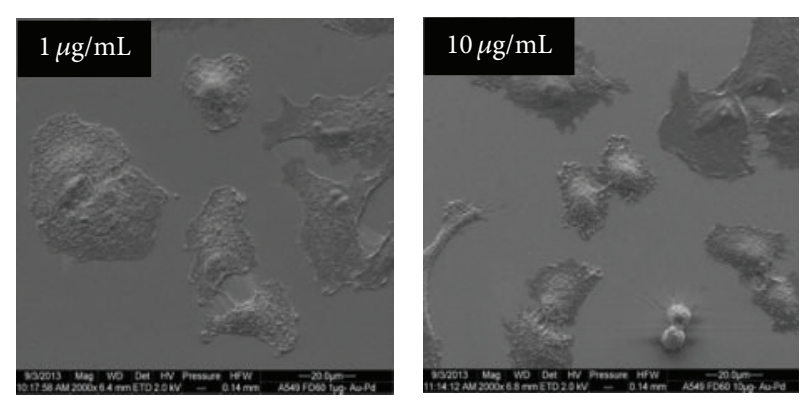
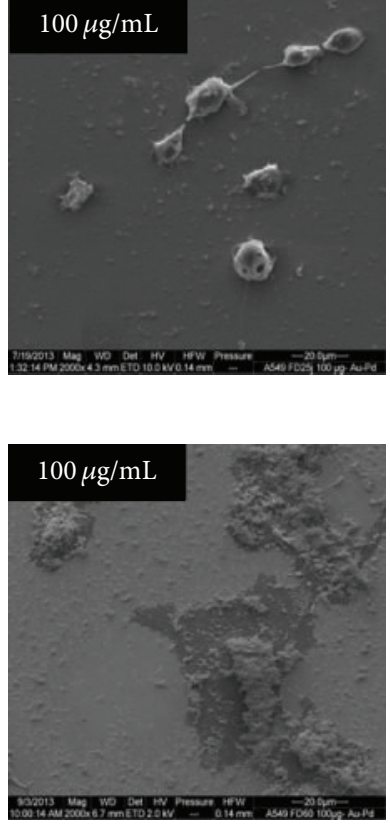

(b)

FIgURE 7: SEM micrographs of A549 cells incubated for $5 \mathrm{~h}$ with Si-25-FD and Si-85-FD in serum-free medium. SiO $\mathrm{S}_{2}$ concentrations of 1 and $10 \mu \mathrm{g} \mathrm{mL} \mathrm{m}^{-1} \mathrm{Si}$-25-FD induced no changes in cell morphology. After exposure to $100 \mu \mathrm{g} \mathrm{mL}^{-1} \mathrm{Si}-25$-FD (a) A549 cells are round in cell shape compared to unexposed cells (ctr). At a concentration of $10 \mu \mathrm{g} \mathrm{mL}^{-1} \mathrm{SiO}_{2}$ and higher, both particle sizes formed agglomerates and bound to the cell membrane. Incubation with 1,10 , or $100 \mu \mathrm{g} \mathrm{mL}{ }^{-1}$ Si-85-FD particles (b) induced no changes in cell morphology.

$150 \mathrm{~nm}$ (10\% in case of the $85 \mathrm{~nm}$ particles) were regarded as particle agglomerates. The largest agglomerate had a width of $578 \mathrm{~nm}$. To estimate the total number of particles within intracellular agglomerates, one-, two-, and threedimensional agglomerate models were applied, assuming packing densities of 0.91 (two-dimensional) and 0.74 (threedimensional), respectively. Taking these models into account, the number of $85 \mathrm{~nm}$ SNPs per cell was estimated to range from 412 in case of one-dimensional agglomerates to 585 representing two-dimensional agglomerates to 957 in case of three-dimensional agglomerates (Additional file 4b).

In comparison, single $25 \mathrm{~nm}$ NPs could not be resolved by STED imaging as indicated by the measured FWHM value $(61 \mathrm{~nm})$ of a sample particle (Figure 2, Table 1). In case of the $25 \mathrm{~nm}$ particles, $58 \%$ of the detected objects had a lateral width of $<75 \mathrm{~nm}$, representing either single particles or small agglomerates. Depending on the agglomeration model applied, the number of $25 \mathrm{~nm}$ SNPs per cell was estimated to range from 404 in case of one-dimensional agglomerates to 1657 representing two-dimensional agglomerates to 7772 in case of three-dimensional agglomerates (Additional file 4a). Thus, taking intracellular particle agglomeration into account, it can be concluded that cells accumulated threeto eightfold higher numbers of the $25 \mathrm{~nm}$ particles compared with the $85 \mathrm{~nm}$ particles.

According to light scattering analysis and analytical centrifugation, the particles used in this study were shown to be well separated, when dispersed in either serum-containing medium or serum-free medium. In contrast, by microscopy large particle agglomerates were observed to cover the cells in the absence of serum.

In a TEM study, Rothen-Rutishauser et al. showed that, after exposing A549 cells to $9 \times 10^{11} 15 \mathrm{~nm}$ polymer-coated gold NPs per milliliter for $1 \mathrm{~h}, 5365$ NPs were internalized by the cells [53]. In comparison to the study described here, the cells were exposed to a significantly higher dose of NPs for a shorter time in absence of serum. After exposing A549 cells to citrate-coated gold NPs in presence of serum, 2600 and 3575 particles were quantified intracellularly after $1 \mathrm{~h}$ and $4 \mathrm{~h}$, respectively [29]. In this case, a dose of $1 \times$ $10^{11}$ particles $\mathrm{mL}^{-1}$ was administered. These values indicate that particle internalization is a time-dependent process, as expected when considering an active accumulation process. Similar trends have been found by Chithrani et al. [23] and Lesniak et al. [11] for the uptake of gold NPs and SNPs, respectively. In addition to time, the extracellular particle concentration is expected to influence uptake efficiency. For example, Chithrani et al. found a saturation of particle internalization for HeLa cells after $5 \mathrm{~h}$ [23].

The observed correlation of the increase in internalization or cell-association of particles with the administered dose was also detected in a recent study applying ICP-MS to particle quantification [24]. Depending on the ratio between the extracellular and intracellular particle concentration, the establishment of an equilibrium state can be expected, resulting in a certain number of particles accumulating intracellularly. All in all, the results from the mentioned studies indicate that, depending on exposure time 


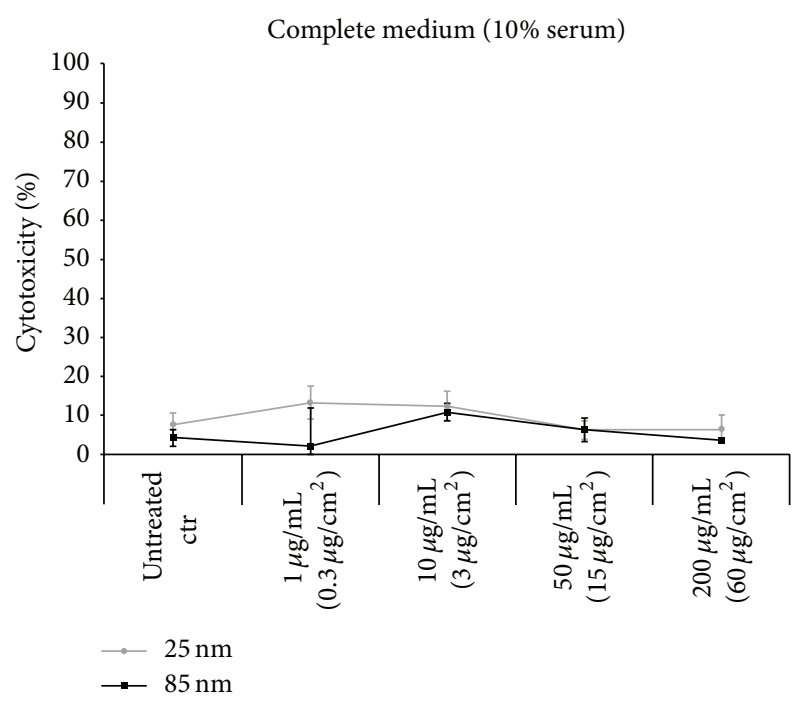

FIGURE 8: No membrane damage in the presence of serum proteins. A549 cells were incubated for $5 \mathrm{~h}$ with increasing concentrations (1, 10,50 , and $200 \mu \mathrm{g} \mathrm{mL}^{-1}$ ) of Si-25 and Si-85 in complete medium (DMEM with $10 \% \mathrm{FBS}$ ). Concentrations in brackets refer to the area of a 12 -well plate. $\mathrm{LDH}$ assay of supernatant was performed and no membrane damage could be observed compared to the unexposed control cells. Percent of cytotoxicity \pm SD of 3 independent experiments is shown.

and administered dose, the number of particles per cell generally varies between $10^{2}$ and $10^{5}$, not accounting for differences in cell or particle type. The results presented here agree well with these previously published findings. Due to the influence of time and extracellular particle concentration, it is important to keep experimental conditions constant for all NP sizes when estimating intracellular NP doses, especially when internalization efficiency is correlated with particle size. For example, Chithrani et al. concluded that $50 \mathrm{~nm}$ particles are internalized with higher efficiency than smaller or larger particles [23]. In this case, the authors did not specify the administered particle concentration and it is unclear if they used identical mass concentrations or particle number concentrations. Assuming the former, the cells would have been exposed to increasing particle concentrations with decreasing particle size. Taking this into account, the larger particles are internalized with higher efficiency [54].

On the other hand, if the concentration value refers to particle number, a comparison between the administered particle number and the internalized particle number implies that uptake efficiency into cells is rather low. A low uptake efficiency was, for example, found by Höcherl et al., concluding that HeLa cells internalized only $10^{-3} \%$ of the initially added negatively charged $160 \mathrm{~nm}$ poly(methyl methacrylate) particles after $2 \mathrm{~h}$ based on flow cytometry and CLSM characterization [55]. In addition to the administered dose, the delivered dose is relevant when calculating uptake efficiency. Gottstein et al. quantified the uptake of 250, 400, and $1000 \mathrm{~nm}$ fluorescent polystyrene particles in J774 macrophages and reported that the number of internalized particles per cell was greater for the smaller particles [49]. More specifically, the

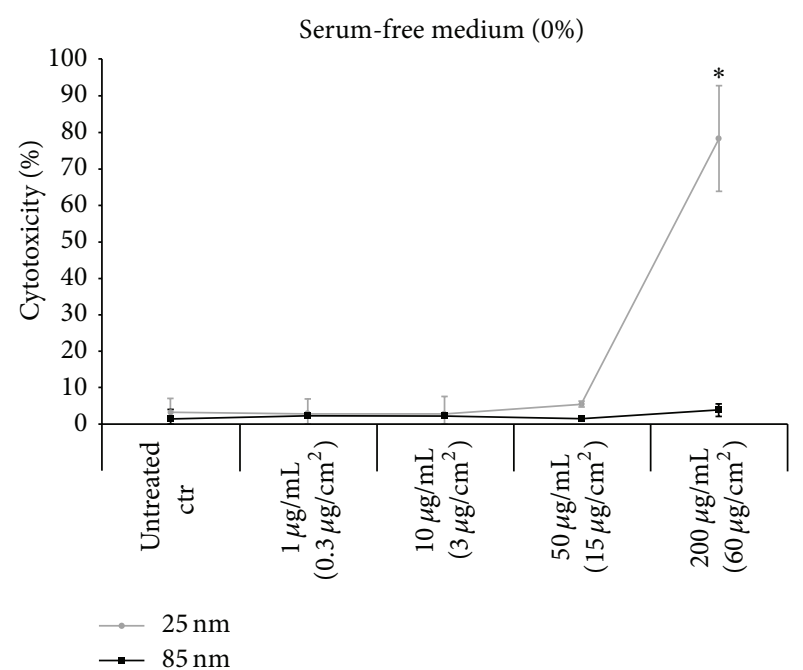

FIGURE 9: Membrane damage in the absence of serum proteins. A549 cells were incubated with increasing concentrations $(1,10,50$, and $200 \mu \mathrm{g} \mathrm{mL}^{-1}$ ) of Si-25 and Si-85 in serum-free medium (DMEM with $0 \%$ FBS). LDH assay was performed after $5 \mathrm{~h}$ incubation. Only exposure to $200 \mu \mathrm{g} \mathrm{mL}^{-1} \mathrm{Si}-25$ induced cell damage compared to unexposed control cells. Error bars represent SD of 3 independent experiments. * Significantly different from untreated controls, $p \leq$ 0.05 .

delivered dose of the smaller particles was of two orders of magnitude higher than the dose of the larger particles.

In this study, by application of the computational ISDD model [22], the delivered particle dose was determined to be similar for both NP sizes, considering separated particles as well as agglomerates of up to four particles, and was approximately $20 \%$ of the administered particle number. Thus, taking the above described agglomeration models into account, $0.1 \%$ up to $5.8 \%$ and $0.3 \%$ up to $0.9 \%$ of the delivered $25 \mathrm{~nm}$ and $85 \mathrm{~nm}$ NPs entered the cells, respectively. With regard to the potential internalization process, some studies on fibroblasts indicate that clathrin-coated pits cover up $2 \%$ of the cell surface and $1 \%$ of the membrane is internalized per minute $[56,57]$. When transferred to the A549 cells used in this study, it can be deduced that $1.5 \times 10^{4}$ vesicles are internalized within $5 \mathrm{~h}$, corresponding well to the number of particles observed to be internalized by the cells. The delivered particle concentration in the fluid column $(h=10 \mu \mathrm{m})$ surrounding the cells was determined to be approximately $2.3 \times 10^{12}$ $\mathrm{NPs} \mathrm{mL}^{-1}$. Based on an average cell volume of $1600 \mu \mathrm{m}^{3}$, it was calculated that the cells internalized $2.5 \times 10^{11}-4.8 \times$ $10^{12}$ particles $\mathrm{mL}^{-1}$. Thus, under the conditions applied, the cells did not appear to accumulate particles in excess of the delivered particle concentration.

4.2. Quantification of NP Uptake via Processing of STED Images. To interpret the results on particle internalization gathered by various methods, the strengths and limitations of these techniques have to be defined, in addition to considering the NP dose and uptake efficiency. First of all, in this study, like in others [55], a large difference in the number 


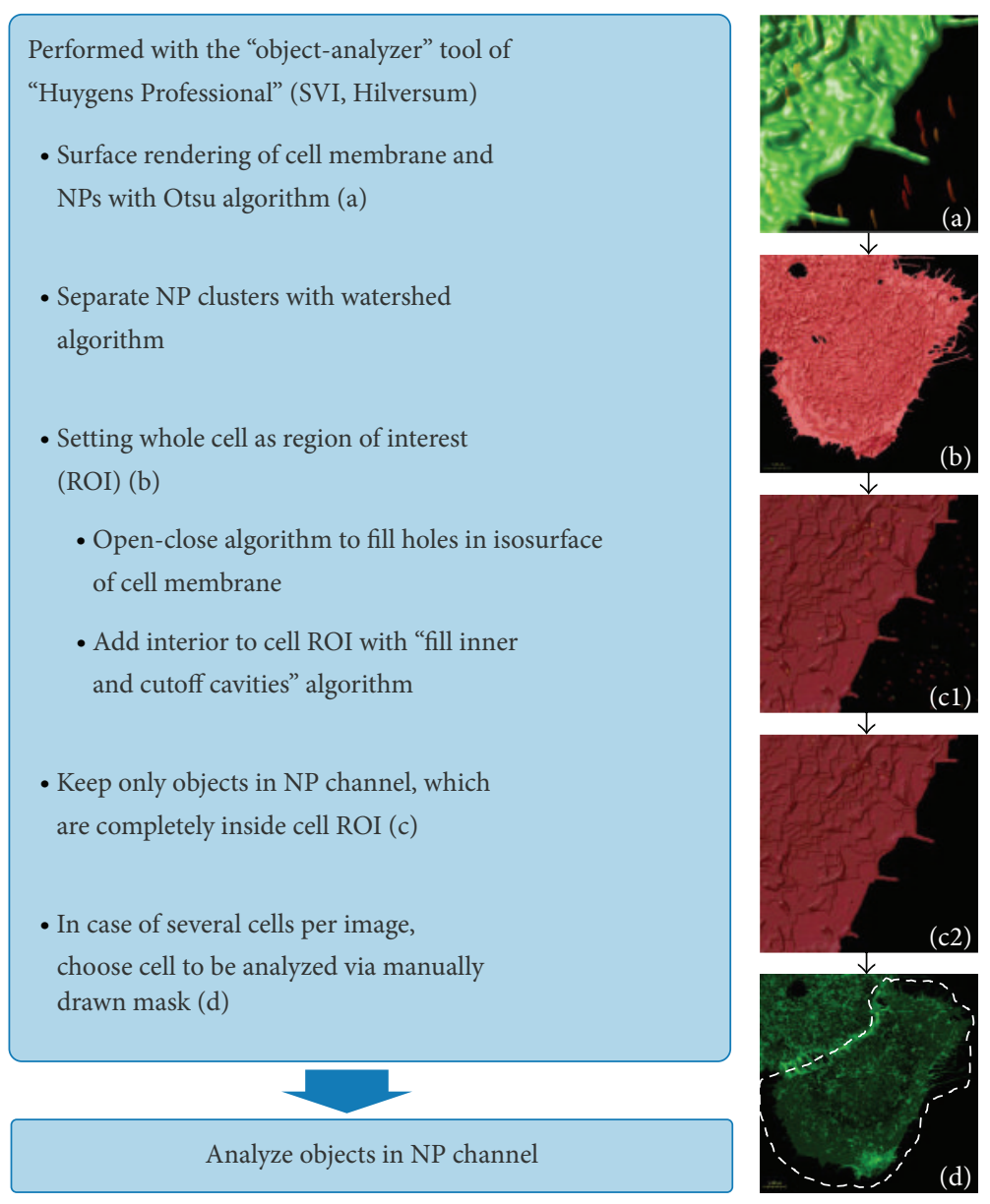

FIGURE 10: Image processing workflow.

of internalized objects from cell to cell was observed. One possible explanation for this is the large variation in cell size (Additional file 2). An additional explanation for this finding, which is that the cell cycle influences uptake efficiency, was reported by Kim et al. [58].

Regarding the STED technique used in this study, high laser intensities are used that induce photobleaching of the fluorescently labeled NPs, which might lead to an underestimation of the number of internalized particles especially in the case of the smaller particles that had a lower overall fluorescence intensity than the larger particles. The number of internalized particles was likely rather underestimated during the process of quantifying internalized NPs, because only objects that were completely inside the segmented cell region of interest (ROI) were counted to ensure that the NPs attached to the cell surface were excluded. In superresolution microscopy, data acquisition on a cell-by-cell basis, as well as image processing, is relatively time-consuming. For this reason it is not a high throughput technique like flow cytometry. Consequently, this results in lower quality statistics and limitations for comparative studies, such as uptake kinetics. An alternative approach used to quantify the internalization of particles that are smaller than the classical optical resolution limit using light microscopy was presented by Torrano et al. [59]. Their approach consisted of utilizing specially developed ImageJ macro (Particle_in_Cell-3D) and prior knowledge about the fluorescence intensity of single particles to analyze confocal image stacks of single cells, which had been exposed to $100 \mathrm{~nm}$ polystyrene particles. Employing this method, the fraction of internalized compared to membrane-associated particles was determined to be $92 \%$ after 5 h $45 \mathrm{~min}$ in HeLa cells. In order to confirm the results obtained from the quantification procedure, the application of a super-resolution microscopy technique (STED) was necessary. In the present study, the quantification of particles internalized by cells in the absence of serum was not possible because large NP agglomerates formed covering the cell membrane of cells in microscopy samples. Applying the watershed algorithm did not permit separation of these agglomerates, because the intensity distributions produced by single particles merged in the case of larger agglomerates. Thus, dividing local minima, detectable by the watershed algorithm, disappeared. Quantifying single particle events under these conditions was therefore not possible. Thus, internalization efficiencies of the NPs could not be compared. However, based on CLSM images, it appeared that more particles/particle agglomerates entered the cells under serumfree conditions. This observation is corroborated by a FACS study, in which A549 cells were found to have increased uptake levels of SNPs under serum-free conditions [11]. 
The authors concluded that the observed tendency of particles to adhere more strongly to the cell membrane under serum-free conditions contributes to the increase in NP uptake. It is important to note that at the particle concentration $\left(9.2 \times 10^{10}\right.$ particles $\left.\mathrm{mL}^{-1}\right)$ employed in our study, which is equivalent to mass concentrations of $1.2 \mu \mathrm{g} \mathrm{SiO} \mathrm{mL}^{-1}$ (25 nm SNPs) and $50 \mu \mathrm{g} \mathrm{SiO} \mathrm{mL}^{-1}$ ( $85 \mathrm{~nm}$ SNPs), no morphological changes or membrane damage was observed that might contribute to the elevated uptake efficiency observed in CLSM images. It cannot, however, be excluded that serumstarving effects might influence cellular responses and uptake processes $[60,61]$.

\subsection{Influence of Serum Proteins on NP Agglomeration and} Cytotoxicity. According to SEM analysis, SNPs were found to bind to the membrane of A549 cells. The amount of particles detected on top of the cells appeared to be positively correlated with NP concentration and was much greater in the presence of serum-free medium than in the presence of serum supplemented medium although as stated above, in absence of serum no agglomeration of NPs was detected by light scattering and analytical centrifugation analyses. Our results corroborate the findings of Lesniak et al. who also observed strong adhesion of SNPs to the membrane of A549 cells in serum-free medium $[11,12]$. They also detected agglomeration of SNPs in the absence of serum proteins by TEM analysis of A549 cells, although a high degree of agglomeration was not observed by light scattering analysis. The authors concluded that cell protrusions, creating some entanglement on top of the cell surface, entrapped the NPs [11].

In this study, in presence of serum no cytotoxicity or change in cell morphology could be observed even at the highest $\mathrm{SiO}_{2}$ concentration used. In absence of serum, membrane damage, measured as $\mathrm{LDH}$ release, was observed only after exposition to the $25 \mathrm{~nm} \mathrm{NPs}$ at the highest $\mathrm{SiO}_{2}$ concentration tested $\left(200 \mu \mathrm{g} \mathrm{mL}^{-1}\right)$. The results indicate that significant membrane damage can also be expected at $100 \mu \mathrm{g} \mathrm{mL}^{-1}$. Therefore, care was taken to perform the uptake studies at subcytotoxic concentrations in order to exclude an influence of membrane damage on unspecific or passive NP uptake [11]. It has been previously reported that the presence of proteins on the surface of SNPs has a protective effect against silica-induced hemolysis and cytotoxicity [13, 62]. Also, Wang et al. have shown that the protein corona protects the cells from damage until the corona proteins are degraded within lysosomes [63]. We observed that the membrane damage induced by $25 \mathrm{~nm}$ SNPs in serum-free medium was reduced not only by addition of serum, like also observed by Kim et al. [64], but also after addition of singleserum proteins like BSA (bovine serum albumin) (Additional file 5). These results agree well with the research performed by Gualtieri et al. which revealed a reduced cytotoxicity of SNPs in the presence of BSA and demonstrated that the surface coating of the particles is primarily responsible for the protective effect [62]. In this study, the absolute value of the zeta potential was found to be reduced in the presence of serum, and thus it is postulated that serum components, like proteins, adsorb to the NP surface. Adsorption of proteins to the NP surface results in the electrosteric stabilization of the particle, preventing particle agglomeration, even in vicinity of the cell surface. The protein corona might also prevent the binding of counter ions, which would reduce repulsive surface charges of the particles. Light scattering analysis indicated that agglomerates formed when higher particle concentrations were dispersed in serum-containing medium (Additional file 1). This trend might explain the contrasting reports on particle agglomeration behavior. In other studies, cytotoxicity, DNA damage, and ROS production were reported after exposing cells to SNPs in serum-containing medium. In addition, lipid peroxidation and disruption of model membranes were found [14, 65]. The divergent agglomeration behavior in serum-containing medium might also be due to various synthesis protocols and stabilization of SNPs. This should be taken into account when comparing results of different studies. In comparison to other studies using commercial nanoparticles or even larger particles [11, 64], the nanoparticles used in this study were custom-made, corroborating the generality of the protective effect of the protein corona.

Our results raise the question of whether intracellular particles, accumulated at relatively low numbers, are generally able to affect the cells or if this is mediated by particles interacting with the cell surface. If one considers particle distribution, a much larger amount of particles is present close to the extracellular side of the cytoplasmic membrane than inside the cell. After exposition of cells to $9.2 \times 10^{10}$ NPs $\mathrm{mL}^{-1}$ and considering particle sedimentation, $6 \%$ and $53 \%$ of the cell surface would be covered by $25 \mathrm{~nm}$ and $85 \mathrm{~nm}$ NPs, respectively. After internalization of $\sim 7000$ particles ( $25 \mathrm{~nm}$ SNPs), a volume of $0.057 \mu \mathrm{m}^{3}$ is occupied by NPs, corresponding to $3.5 \times 10^{-5}$ part of the cell volume. Nevertheless, in this study, membrane damage was only detected at high external NP concentrations (> $50 \mu \mathrm{g} \mathrm{mL}^{-1}$ of $25 \mathrm{~nm}$ SNPs $\mathrm{SiO}_{2}$ corresponding to $9.2 \times 10^{12} \mathrm{NPs} \mathrm{mL}^{-1}$ ) in the absence of serum. Considering $22 \%$ particle sedimentation, at that particle concentration, the cellular surface would be more than completely covered by SNPs, indicating that membrane damage in absence of serum is initiated by direct contact of particles to the cellular surface accompanied by interaction of particles with membrane constituents.

\section{Conclusions}

This study demonstrated for the first time that quantitative estimates of the number of NPs internalized by epithelial cells can be extracted from 3D STED image stacks of entire cells via image processing. The approach used here was based on the number of intracellular fluorescent objects instead of the fluorescence intensity associated with one single cell. The internalization of $25 \mathrm{~nm}$ and $85 \mathrm{~nm}$ SNPs exposed to A549 lung epithelial cells was compared using equal particle number concentrations. Uptake studies were performed at subcytotoxic concentrations in order to exclude an influence of membrane damage on NP uptake. $10^{2}-10^{3}$ particles per cell were determined after $5 \mathrm{~h}$ exposure in serum-containing 
medium, taking the number of particles into account that were contained within agglomerates. Although the intracellular particle concentration exceeded the initially administered particle concentration, no significant intracellular accumulation of particles above the delivered particle concentration, as determined by application of the ISDD model, was observed. By providing quantitative analyses of administered, delivered, and intracellular NPs, our study contributes to quantitative insights into nanoparticle-cell interactions. This knowledge is essential for risk assessment and safe by design approaches in nanotechnology. Future in vitro studies using various initial particle number concentrations and exposition times are necessary in order to elucidate uptake kinetics and relationships between intracellular and extracellular particle concentrations.

\section{Conflict of Interests}

The authors declare that they have no competing interests.

\section{Authors' Contribution}

Henrike Peuschel and Thomas Ruckelshausen contributed equally to this work. Thomas Ruckelshausen and Henrike Peuschel designed the study. Henrike Peuschel performed the cell experiments. Thomas Ruckelshausen performed the image processing of STED and EM images. Christian Cavelius performed particle synthesis and characterization. Annette Kraegeloh and all authors contributed to the interpretation of data, the preparation of the paper, and approval of the final version.

\section{Acknowledgments}

The authors thank Justin G. Teeguarden for the provision of the ISDD model code. The authors also thank Anika Schwarz and Sarah Schmidt for assistance in particle synthesis and physicochemical particle characterization, Marcus Koch for excellent EM investigation, Nathalie Guimard for proofreading the paper, and Karsten Moh for helpful discussion regarding particle agglomeration models (all INM). The authors thank Eduard Arzt for the continuing support of their work at INM.

\section{References}

[1] "Types and uses of nanomaterials, including safety aspects," Comission Staff Working Paper, European Comission, 2012.

[2] R. Merget, T. Bauer, H. Küpper et al., "Health hazards due to the inhalation of amorphous silica," Archives of Toxicology, vol. 75, no. 11, pp. 625-634, 2002.

[3] T. G. Smijs and S. Pavel, "Titanium dioxide and zinc oxide nanoparticles in sunscreens: focus on their safety and effectiveness," Nanotechnology, Science and Applications, vol. 4, no. 1, pp. 95-112, 2011.

[4] S. Dekkers, P. Krystek, R. J. B. Peters et al., "Presence and risks of nanosilica in food products," Nanotoxicology, vol. 5, no. 3, pp. 393-405, 2011.
[5] Y.-X. J. Wang, "Superparamagnetic iron oxide based MRI contrast agents: current status of clinical application," Quantitative Imaging in Medicine and Surgery, vol. 1, no. 1, pp. 35-40, 2011.

[6] M. F. L. de Volder, S. H. Tawfick, R. H. Baughman, and A. J. Hart, "Carbon nanotubes: present and future commercial applications," Science, vol. 339, no. 6119, pp. 535-539, 2013.

[7] T. H. Kim, S. Lee, and X. Chen, "Nanotheranostics for personalized medicine," Expert Review of Molecular Diagnostics, vol. 13, no. 3, pp. 257-269, 2013.

[8] K. Unfried, C. Albrecht, L.-O. Klotz, A. von Mikecz, S. GretherBeck, and R. P. F. Schins, "Cellular responses to nanoparticles: target structures and mechanisms," Nanotoxicology, vol. 1, no. 1, pp. 52-71, 2007.

[9] F. Zhao, Y. Zhao, Y. Liu, X. Chang, C. Chen, and Y. Zhao, "Cellular uptake, intracellular trafficking, and cytotoxicity of nanomaterials," Small, vol. 7, no. 10, pp. 1322-1337, 2011.

[10] L. Treuel, X. Jiang, and G. U. Nienhaus, "New views on cellular uptake and trafficking of manufactured nanoparticles," Journal of the Royal Society, vol. 10, pp. 1-14, 2013.

[11] A. Lesniak, F. Fenaroli, M. P. Monopoli, C. Åberg, K. A. Dawson, and A. Salvati, "Effects of the presence or absence of a protein corona on silica nanoparticle uptake and impact on cells," ACS Nano, vol. 6, no. 7, pp. 5845-5857, 2012.

[12] A. Lesniak, A. Salvati, M. J. Santos-Martinez, M. W. Radomski, K. A. Dawson, and C. Åberg, "Nanoparticle adhesion to the cell membrane and its effect on nanoparticle uptake efficiency," Journal of the American Chemical Society, vol. 135, no. 4, pp. 1438-1444, 2013.

[13] J. Shi, Y. Hedberg, M. Lundin, I. O. Wallinder, H. L. Karlsson, and L. Möller, "Hemolytic properties of synthetic nano- and porous silica particles: the effect of surface properties and the protection by the plasma corona," Acta Biomaterialia, vol. 8, no. 9, pp. 3478-3490, 2012.

[14] W. Lin, Y.-W. Huang, X.-D. Zhou, and Y. Ma, "In vitro toxicity of silica nanoparticles in human lung cancer cells," Toxicology and Applied Pharmacology, vol. 217, no. 3, pp. 252-259, 2006.

[15] M. Ahamed, "Silica nanoparticles-induced cytotoxicity, oxidative stress and apoptosis in cultured A431 and A549 cells," Human and Experimental Toxicology, vol. 32, no. 2, pp. 186-195, 2013.

[16] F. Wang, F. Gao, M. Lan, H. Yuan, Y. Huang, and J. Liu, “Oxidative stress contributes to silica nanoparticle-induced cytotoxicity in human embryonic kidney cells," Toxicology in Vitro, vol. 23, no. 5, pp. 808-815, 2009.

[17] S. Schubbe, C. Cavelius, C. Schumann, M. Koch, and A. Kraegeloh, "STED microscopy to monitor agglomeration of silica particles inside A549 cells," Advanced Engineering Materials, vol. 12, no. 5, pp. 417-422, 2010.

[18] C. Uboldi, G. Giudetti, F. Broggi, D. Gilliland, J. Ponti, and F. Rossi, "Amorphous silica nanoparticles do not induce cytotoxicity, cell transformation or genotoxicity in Balb/3T3 mouse fibroblasts," Mutation Research-Genetic Toxicology and Environmental Mutagenesis, vol. 745, no. 1-2, pp. 11-20, 2012.

[19] R. Ahmad Khanbeigi, A. Kumar, F. Sadouki et al., "The delivered dose: applying particokinetics to in vitro investigations of nanoparticle internalization by macrophages," Journal of Controlled Release, vol. 162, no. 2, pp. 259-266, 2012.

[20] M. Geiser and W. G. Kreyling, "Deposition and biokinetics of inhaled nanoparticles," Particle and Fibre Toxicology, vol. 7, article 2, 2010. 
[21] J. G. Teeguarden, P. M. Hinderliter, G. Orr, B. D. Thrall, and J. G. Pounds, "Particokinetics in vitro: dosimetry considerations for in vitro nanoparticle toxicity assessments," Toxicological Sciences, vol. 95, no. 2, pp. 300-312, 2007.

[22] P. M. Hinderliter, K. R. Minard, G. Orr et al., "ISDD: A computational model of particle sedimentation, diffusion and target cell dosimetry for in vitro toxicity studies," Particle and Fibre Toxicology, vol. 7, article 36, 2010.

[23] B. D. Chithrani, A. A. Ghazani, and W. C. W. Chan, "Determining the size and shape dependence of gold nanoparticle uptake into mammalian cells," Nano Letters, vol. 6, no. 4, pp. 662-668, 2006.

[24] D. Drescher, C. Giesen, H. Traub, U. Panne, J. Kneipp, and N. Jakubowski, "Quantitative imaging of gold and silver nanoparticles in single eukaryotic cells by laser ablation ICP-MS," Analytical Chemistry, vol. 84, no. 22, pp. 9684-9688, 2012.

[25] X. He, Y. Ma, M. Li, P. Zhang, Y. Li, and Z. Zhang, "Quantifying and imaging engineered nanomaterials in vivo: challenges and techniques," Small, vol. 9, no. 9-10, pp. 1482-1491, 2013.

[26] A. Neumeyer, M. Bukowski, M. Veith, C.-M. Lehr, and N. Daum, "Propidium iodide labeling of nanoparticles as a novel tool for the quantification of cellular binding and uptake," Nanomedicine: Nanotechnology, Biology, and Medicine, vol. 7, no. 4, pp. 410-419, 2011.

[27] S. Vranic, N. Boggetto, V. Contremoulins et al., "Deciphering the mechanisms of cellular uptake of engineered nanoparticles by accurate evaluation of internalization using imaging flow cytometry," Particle and Fibre Toxicology, vol. 10, article 2, 2013.

[28] A. Elsaesser, A. Taylor, G. S. de Yanés et al., "Quantification of nanoparticle uptake by cells using microscopical and analytical techniques," Nanomedicine, vol. 5, no. 9, pp. 1447-1457, 2010.

[29] C. Brandenberger, C. Mühlfeld, Z. Ali et al., "Quantitative evaluation of cellular uptake and trafficking of plain and polyethylene glycol-coated gold nanoparticles," Small, vol. 6, no. 15, pp. 16691678, 2010.

[30] C. Schumann, S. Schübbe, C. Cavelius, and A. Kraegeloh, "A correlative approach at characterizing nanoparticle mobility and interactions after cellular uptake," Journal of Biophotonics, vol. 5, no. 2, pp. 117-127, 2012.

[31] K. Shapero, F. Fenaroli, I. Lynch, D. C. Cottell, A. Salvati, and K. A. Dawson, "Time and space resolved uptake study of silica nanoparticles by human cells," Molecular BioSystems, vol. 7, no. 2, pp. 371-378, 2011.

[32] Commission Recommendation on the Definition of Nanomaterial, European Comission, 2011.

[33] S. W. Hell, S. Lindek, C. Cremer, and E. H. K. Stelzer, "Measurement of the $4 \mathrm{Pi}$-confocal point spread function proves 75 nm axial resolution," Applied Physics Letters, vol. 64, no. 11, pp. 1335-1337, 1994.

[34] M. G. L. Gustafsson, D. A. Agard, and J. W. Sedat, "I ${ }^{5} M$ : 3D widefield light microscopy with better than $100 \mathrm{~nm}$ axial resolution," Journal of Microscopy, vol. 195, no. 1, pp. 10-16, 1999.

[35] M. G. L. Gustafsson, "Surpassing the lateral resolution limit by a factor of two using structured illumination microscopy," Journal of Microscopy, vol. 198, no. 2, pp. 82-87, 2000.

[36] R. Heintzmann, T. M. Jovin, and C. Cremer, "Saturated patterned excitation microscopy-a concept for optical resolution improvement," Journal of the Optical Society of America A: Optics and Image Science, and Vision, vol. 19, no. 8, pp. 15991609, 2002.
[37] J. Reymann, D. Baddeley, M. Gunkel et al., "High-precision structural analysis of subnuclear complexes in fixed and live cells via spatially modulated illumination (SMI) microscopy," Chromosome Research, vol. 16, no. 3, pp. 367-382, 2008.

[38] S. W. Hell and J. Wichmann, "Breaking the diffraction resolution limit by stimulated emission: stimulated-emissiondepletion fluorescence microscopy," Optics Letters, vol. 19, no. 11, pp. 780-782, 1994.

[39] E. Betzig, G. H. Patterson, R. Sougrat et al., "Imaging intracellular fluorescent proteins at nanometer resolution," Science, vol. 313, no. 5793, pp. 1642-1645, 2006.

[40] M. J. Rust, M. Bates, and X. Zhuang, "Sub-diffractionlimit imaging by stochastic optical reconstruction microscopy (STORM)," Nature Methods, vol. 3, no. 10, pp. 793-795, 2006.

[41] S. T. Hess, T. P. K. Girirajan, and M. D. Mason, "Ultra-high resolution imaging by fluorescence photoactivation localization microscopy," Biophysical Journal, vol. 91, no. 11, pp. 4258-4272, 2006.

[42] A. Egner, C. Geisler, C. von Middendorff et al., "Fluorescence nanoscopy in whole cells by asynchronous localization of photoswitching emitters," Biophysical Journal, vol. 93, no. 9, pp. 3285-3290, 2007.

[43] M. Heilemann, S. Van De Linde, M. Schüttpelz et al., "Subdiffraction-resolution fluorescence imaging with conventional fluorescent probes," Angewandte Chemie International Edition, vol. 47, no. 33, pp. 6172-6176, 2008.

[44] J. Fölling, M. Bossi, H. Bock et al., "Fluorescence nanoscopy by ground-state depletion and single-molecule return," Nature Methods, vol. 5, no. 11, pp. 943-945, 2008.

[45] P. Lemmer, M. Gunkel, Y. Weiland et al., "Using conventional fluorescent markers for far-field fluorescence localization nanoscopy allows resolution in the $10-\mathrm{nm}$ range," Journal of Microscopy, vol. 235, no. 2, pp. 163-171, 2009.

[46] D. T. Burnette, P. Sengupta, Y. Dai, J. Lippincott-Schwartz, and B. Kachar, "Bleaching/blinking assisted localization microscopy for superresolution imaging using standard fluorescent molecules," Proceedings of the National Academy of Sciences of the United States of America, vol. 108, no. 52, pp. 21081-21086, 2011.

[47] S. Schübbe, C. Schumann, C. Cavelius, M. Koch, T. Müller, and A. Kraegeloh, "Size-dependent localization and quantitative evaluation of the intracellular migration of silica nanoparticles in Caco-2 cells," Chemistry of Materials, vol. 24, no. 5, pp. 914923, 2012.

[48] X. Jiang, C. Röcker, M. Hafner, S. Brandholt, R. M. Dörlich, and G. U. Nienhaus, "Endo- and exocytosis of zwitterionic quantum dot nanoparticles by live hela cells," ACS Nano, vol. 4, no. 11, pp. 6787-6797, 2010.

[49] C. Gottstein, G. Wu, B. J. Wong, and J. A. Zasadzinski, "Precise quantification of nanoparticle internalization," ACS Nano, vol. 7, no. 6, pp. 4933-4945, 2013.

[50] M. Kucki, Detection and Semi-Quantification of Endotoxin Contaminations in Nanoparticle Suspensions-Limulus Amebocyte Lysate (LAL) Gel Clot Assay, DaNa Project, 2012.

[51] N. Otsu, "A threshold selection method from gray-level histograms," IEEE Transactions on Systems, Man and Cybernetics, vol. 9, no. 1, pp. 62-66, 1979.

[52] C. Schulze, A. Kroll, C.-M. Lehr et al., "Not ready to useovercoming pitfalls when dispersing nanoparticles in physiological media," Nanotoxicology, vol. 2, no. 2, pp. 51-61, 2008. 
[53] B. Rothen-Rutishauser, D. A. Kuhn, Z. Ali et al., "Quantification of gold nanoparticle cell uptake under controlled biological conditions and adequate resolution," Nanomedicine, vol. 9, no. 5, pp. 607-621, 2013.

[54] H. J. Johnston, M. Semmler-Behnke, D. M. Brown, W. Kreyling, L. Tran, and V. Stone, "Evaluating the uptake and intracellular fate of polystyrene nanoparticles by primary and hepatocyte cell lines in vitro," Toxicology and Applied Pharmacology, vol. 242, no. 1, pp. 66-78, 2010.

[55] A. Höcherl, K. Landfester, and V. Mailänder, "Absolute quantitation of sub-micrometer particles in cells by flow cytometry," Macromolecular Bioscience, vol. 13, no. 11, pp. 1568-1575, 2013.

[56] R. M. Steinman, I. S. Mellman, W. A. Muller, and Z. A. Cohn, "Endocytosis and the recycling of plasma membrane," The Journal of Cell Biology, vol. 96, no. 1, pp. 1-27, 1983.

[57] I. Mellman, "Endocytosis and molecular sorting," Annual Review of Cell and Developmental Biology, vol. 12, pp. 575-625, 1996.

[58] J. A. Kim, C. Aberg, A. Salvati, and K. A. Dawson, "Role of cell cycle on the cellular uptake and dilution of nanoparticles in a cell population," Nature Nanotechnology, vol. 7, no. 1, pp. 62-68, 2012.

[59] A. A. Torrano, J. Blechinger, C. Osseforth et al., "A fast analysis method to quantify nanoparticle uptake on a single cell level," Nanomedicine, vol. 8, no. 11, pp. 1815-1828, 2013.

[60] S. Pirkmajer and A. V. Chibalin, "Serum starvation: caveat emptor," The American Journal of Physiology-Cell Physiology, vol. 301, no. 2, pp. C272-C279, 2011.

[61] S. K. Tacheva-Grigorova, A. J. M. Santos, E. Boucrot, and T. Kirchhausen, "Clathrin-mediated endocytosis persists during unperturbed mitosis," Cell Reports, vol. 4, no. 4, pp. 659-668, 2013.

[62] M. Gualtieri, T. Skuland, T.-G. Iversen et al., "Importance of agglomeration state and exposure conditions for uptake and pro-inflammatory responses to amorphous silica nanoparticles in bronchial epithelial cells," Nanotoxicology, vol. 6, no. 7, pp. 700-712, 2012.

[63] F. Wang, L. Yu, M. P. Monopoli et al., "The biomolecular corona is retained during nanoparticle uptake and protects the cells from the damage induced by cationic nanoparticles until degraded in the lysosomes," Nanomedicine: Nanotechnology, Biology, and Medicine, vol. 9, no. 8, pp. 1159-1168, 2013.

[64] J. A. Kim, A. Salvati, C. Åberg, and K. A. Dawson, "Suppression of nanoparticle cytotoxicity approaching in vivo serum concentrations: limitations of in vitro testing for nanosafety," Nanoscale, vol. 6, no. 23, pp. 14180-14184, 2014.

[65] Q. Mu, N. S. Hondow, Ł. Krzemiński, A. P. Brown, L. J. C. Jeuken, and M. N. Routledge, "Mechanism of cellular uptake of genotoxic silica nanoparticles," Particle and Fibre Toxicology, vol. 9, article 29, 2012. 

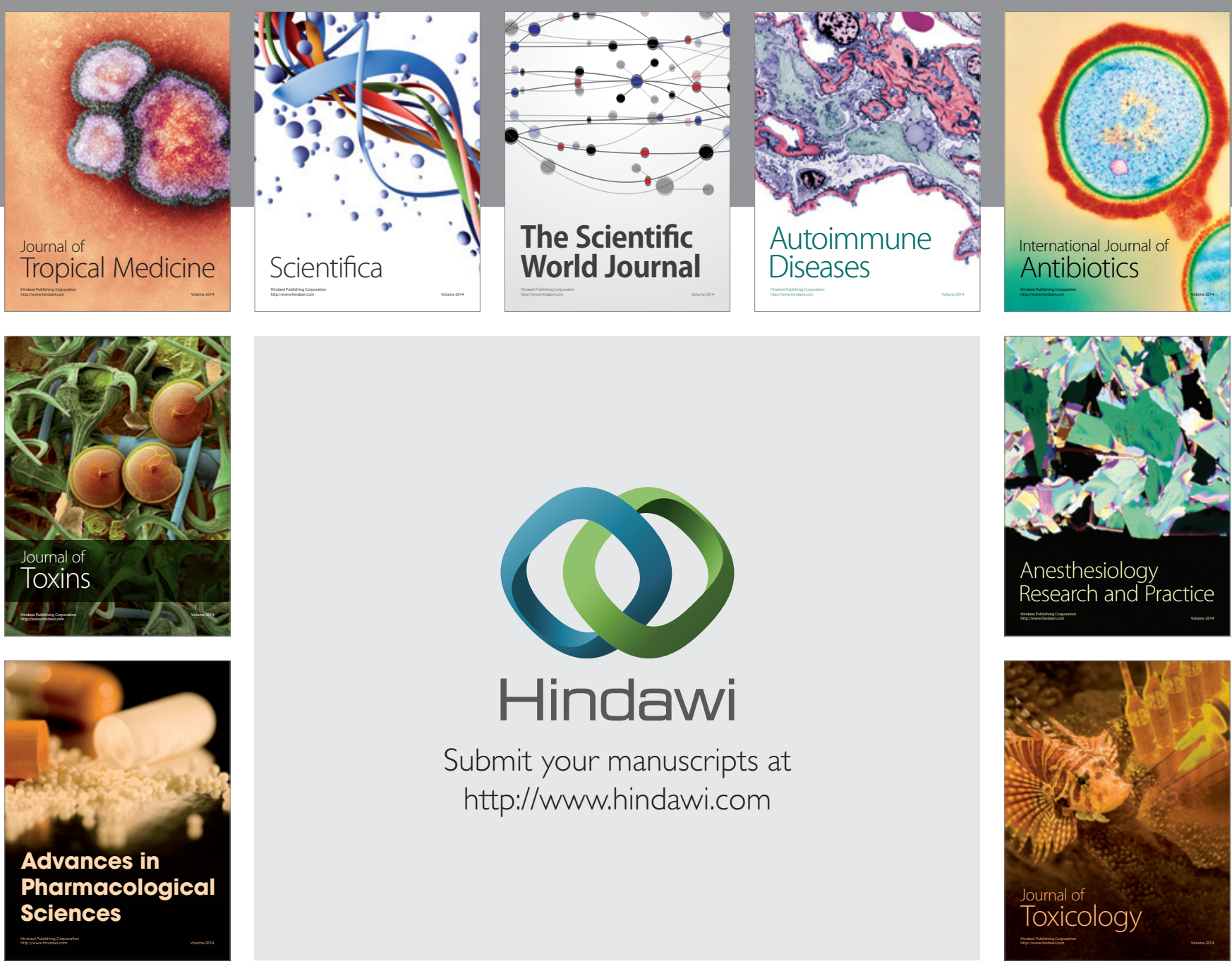

\section{Hindawi}

Submit your manuscripts at

http://www.hindawi.com
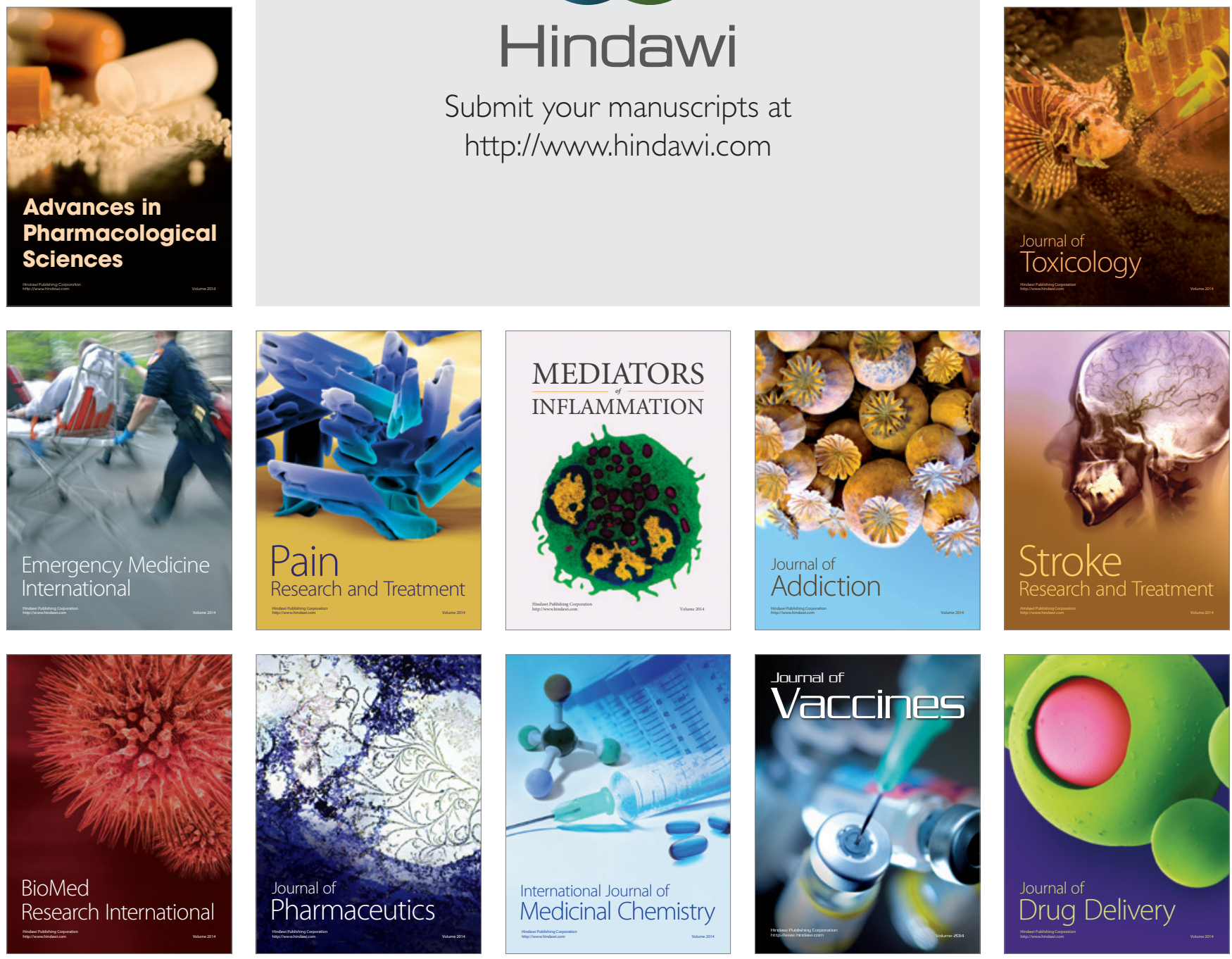